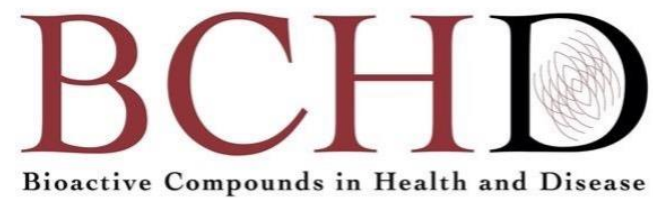

\title{
COVID-19: human immune response and the influence of food ingredients and active compounds
}

\author{
Raphael D. Ayivi ${ }^{1}$, Salam A. Ibrahim ${ }^{1 *}$, Heather L. Colleran ${ }^{1}$, Roberta C. Silva ${ }^{1}$, Leonard L. \\ Williams $^{2}$, Charis M. Galanakis ${ }^{3}$, Hafize Fidan ${ }^{4}$, Julijana Tomovska5 ${ }^{5}$, Shahida Anusha Siddiqui ${ }^{6,7}$ \\ ${ }^{1}$ Food and Nutritional Sciences Program, North Carolina A\&T State University, Greensboro, North Carolina, United \\ States; ${ }^{2}$ Center for Excellence in Post-Harvest Technologies, North Carolina A\&T State University, Kannapolis North \\ Carolina, United States; ${ }^{3}$ Research \& Innovation Department, Galanakis Laboratories, Chania, Greece; ${ }^{4}$ Department \\ of Nutrition and Tourism, University of Food Technologies, Plovdiv, Bulgaria; ${ }^{5}$ Faculty of Biotechnical Sciences, \\ University, St. Kliment Ohridski", Partizanska bb" 7000 Bitola, North Macedonia; "Department of Biotechnology and \\ Sustainability, Technical University of Munich (TUM), Straubing, Germany; ${ }^{7}$ DIL e.V., German Institute of Food \\ Technologies, D-Quakenbruck, Germany.
}

*Corresponding author: Salam A. Ibrahim, Food and Nutritional Sciences Program, North Carolina A\&T State University, Greensboro, North Carolina, United States.

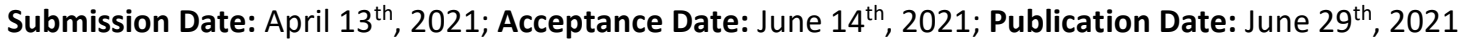

Please cite this article as: Ayivi RD., Ibrahim SA., Colleran HL., Silva RC., Williams LL., Galanakis CM., Fidan H. Tomovska J., Siddiqui SA. COVID-19: human immune response and the influence of food ingredients and active compounds. Bioactive Compounds in Health and Disease. 2021; 4(6): 100-148. DOI: https://www.doi.org/10.31989/bchd.v4i6.802

\section{ABSTRACT}

The human immune system is the first line of defense in the prevention of viruses and diseases, and several immune response mechanisms are engaged at the onset of a pathogenic attack. In this review, we elucidate the human immune system as a critical element in protecting humans from COVID-19 by describing the immune process, explaining how the immune system functions, and highlighting the immune system's global importance in fighting infections. Potential challenges that limit the proper functioning of the immune system are also discussed. In addition, we address the impact of nutrition on boosting the body's defenses against COVID-19. For example, some foods and active compounds from food ingredients have been suggested as a way to strengthen the immune system. Physical exercise has also been encouraged as an important way to support the immune response to viral infections. The aim of this review is thus to outline holistic self-defense immunity mechanisms that can help to reduce the risk of viral infections in humans. This review could therefore be used as a comprehensive resource for educating consumers and the general public about measures that can enhance the body's immune support system as we continue to fight COVID-19 and its variants. 


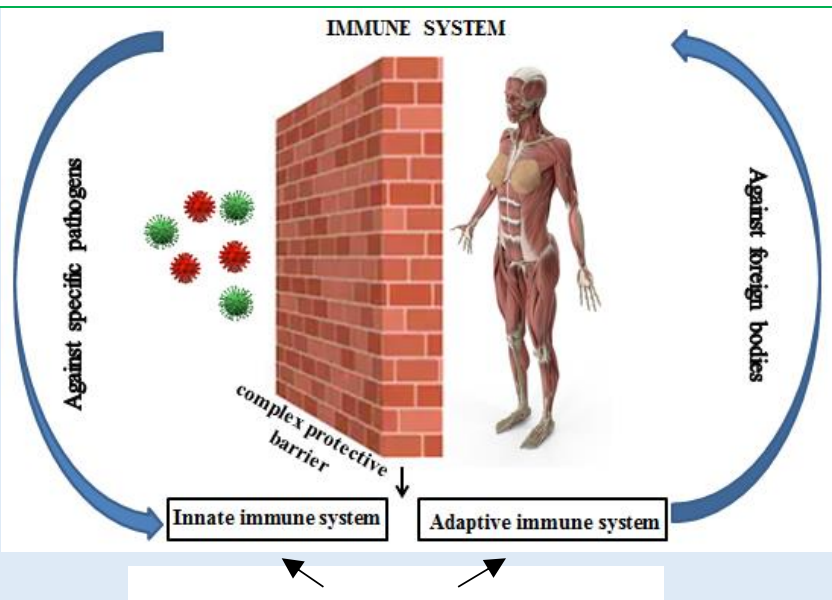

Vitamins and Mineral rich

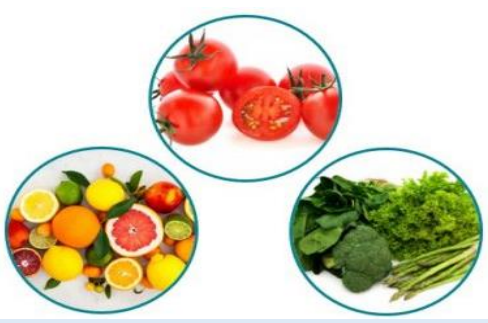

Keywords: Immunity, Covid-19 COVID-19, Nutrition, Bioactive compounds, Food Ingredients

CFFC 2021. This is an Open Access article distributed under the terms of the Creative Commons Attribution 4.0 License (http://creativecommons.org/licenses/by/4.0)

\section{INTRODUCTION}

Coronaviruses are a large group of viruses that are associated with the family Coronaviridae, sub-family Orthocoronavirinae. These viruses typically thrive well in host environments that support their metabolic activities and are zoonotic in nature. Coronaviruses have been notably reported to cause various acute respiratory diseases in humans other than the common cold, and their host reservoirs are largely humans and animals [1]. Human coronaviruses were first identified in the mid-1960s. However, the world's first major outbreaks associated with these viruses occurred between 2002-2003 with Severe Acute Respiratory Syndrome (SARS) and in 2011 with Middle East Respiratory Syndrome (MERS). It was confirmed that novel coronavirus strains in the genus betacoronavirus with zoonotic origin were the causative agents for SARS-CoV and MERS-Cov [2-3]. The present strain of the novel coronavirus SARS-CoV2 was first noticed in December 2019 in Wuhan, China and thusly named COVID-19 [4]. Many people who were infected by COVID-19 were diagnosed with acute respiratory illnesses. Groups identified as being at the highest risk of fatalities from the virus included the elderly and children. Moreover, elderly persons suffering from co-morbidities such as heart disease, lung disease and diabetes, were shown to be at a higher risk of developing severe COVID-19 illness [5]. Generally, people with compromised and very weak 
immune systems tended to be the most vulnerable to COVID-19 [6].

Due to the high number of cases and the high mortality rates, viral infections such as COVID-19 are a major global health problem. As the world awaits effective anti-viral drugs and vaccines to combat this pandemic, the principal defense at this time is an alternative such as strengthening the human immune system. The human body has many protective barriers such as the skin, mucous membrane, tears, saliva, and gastrointestinal defensive barriers that help to protect against various pathogens and viruses. The immune system becomes involved in the process after an invader overcomes these protective barriers. The immune system protects the body from infection through a multi-layered defense with increasing specificity. When the body is initially exposed to pathogens such as bacteria or viruses, physical barriers help to prevent the pathogens from entering the body. However, if a pathogen succeeds in passing through these barriers, the innate immune system reacts immediately but nonspecifically. All plants and animals have innate immunity [7]. If pathogens manage to enter the body despite the efforts of the innate immune system and other defense mechanisms, the body activates another level of protection known as the adaptive (acquired) immune system. The adaptive immune system is specialized and fights specific pathogens. This improved response in the form of immunological memory persists even after the elimination of the pathogen, which allows the immune system to respond more quickly and effectively to the re-emergence of the pathogen. The adaptive immune system thus registers the invaders and enters this information into what is referred to as immunological memory [8].
Consequently, should the pathogen emerge again, the body's immune system will recognize it and immediately activate the acquired immune response. In this way, the body can react quickly and efficiently against infections. The aim of this review is thus to outline holistic self-defense immunity mechanisms that can help to reduce the risk of viral infections. In addition, we focus on the role of nutrition, physical exercise and active compounds from food ingredients in helping to boost the immune system's defenses against COVID-19 prior to interventions with drugs and vaccinations.

\section{REVIEW}

Overview of the Human Immune System: The global impact of infection and disease on human health is of great concern. Global pandemics have the potential to wreak havoc on the physical and mental health of humans in addition to interrupting the food supply and inflicting catastrophic economic losses on affected countries [9-10]. In the wake of the currently devastating COVID-19 pandemic, it has become imperative to focus attention on ways to boost the body's first line of natural defense which is the immune system rather than concentrating solely on the conventional use of vaccine prophylaxis and other antiviral therapies [11]. A broader look at what the human immune system does in response to attacks from pathogens and other microbial infections is thus highly warranted. The immune system is a complex protective barrier that acts in response to any foreign agent that invades the human body and, as a result, shields and defends the body from infectious agents that are present in the host's environment [12-13]. Pathogens pose the greatest risk to a human host and have a spectrum of pathologically linked mechanisms that ultimately endanger the host's cells. Pathogens, 
therefore, are disease-causing microorganisms that pose a threat to human health. In response to an invasion of pathogens, an arsenal of protective mechanisms are unleashed by the immune system with the sole objective of neutralizing and eliminating the pathogens [13]. The immune system is ultimately a sophisticated system that has a varied spectrum of destructive potential to deal with both toxic and allergenic substances but mostly pathogenic ones [8].

Pathogens possess unique structural characteristics that distinguish them from the host cells. As a result, it is easy for immune mechanisms to detect pathogens. Moreover, host-pathogen discrimination is vital as it allows the host to exercise the destruction of the pathogens with minimal damage to host tissues [13]. Also, it is paramount for the host's immune response system to rapidly recognize its tissues during a pathogenic invasion, thereby avoiding inadvertent self-destruction. Self- tolerance is the term that refers to the activation of the host's immune response that efficiently limits and prevents self-damage to its tissues [8]. The immune response system includes two categories: (1) the innate or natural immune system and, (2) the acquired or adaptive immune system. The primary function of the innate immune system is to rapidly prevent the proliferation of foreign bodies or pathogens throughout the body and to serve as the body's first line of defense. The innate immune response has a non-specific defensive approach towards pathogens. The adaptive immune response functions based on specificity.

It is directed at invading pathogens and serves as the second line of defense after the innate immune response has been initiated [12]. Figure 1 shows schematic illustrations of both the innate and the adaptive immune functions.
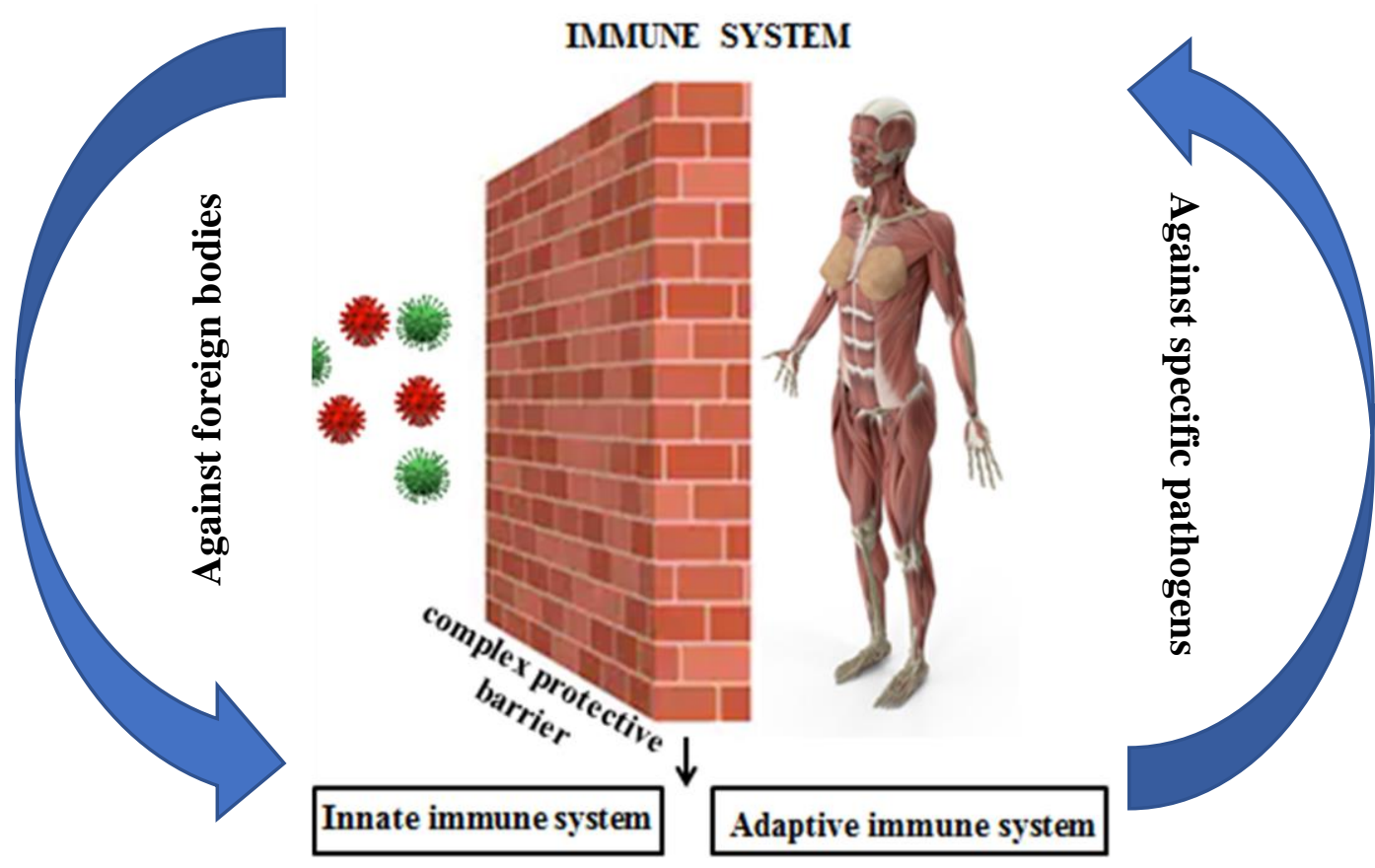

Figure 1. An illustration of the innate and adaptive immune system 
A myriad of blood-borne factors (a complement system that is composed of proteins, antibodies, cytokines) and cells are inherent in these two types of immune system responses. In general, the immune system comprises the white blood cells, complement system, antibodies, lymphatic system, bone marrow, spleen and thymus. The cells associated with the immune system are referred to as leucocytes, otherwise known as white blood cells. The white blood cells or leucocytes are themselves categorized into phagocytes (which comprises granulocytes (neutrophils, basophils, eosinophils), monocytes and macrophages) and lymphocytes [12]. The lymphocytes include T lymphocytes, B lymphocytes, and natural killer cells. T lymphocytes could also be sub-grouped into helper T cells (with CD4 molecules for surface attachment) and cytotoxic $T$ cells (that have CD8 molecules as a surface attachment). The bone marrow is ascribed as the focal point of immune cell evolvement. Immune cells circulate in the bloodstream and are aligned with the lymphoid organs such as in the thymus, spleen, lymph nodes, and gut-related lymphoid tissue, or found disseminated in other parts of the body [12].

The innate immune response is characteristic of rapid stimuli that are nonspecific towards pathogens. Innate immunity is also comprised of physical, chemical, and biological barriers, soluble molecules, and specialized cells that exist in all humans. For Example, tears and mucus secretions trap and inhibit pathogens that enter the human body. Cilia found in the nasal passages and respiratory tract also pushes away mucus containing pathogens out of the body [14].
Innate immune responses are associated with hard-wired communications that are gene encoded in the host's germline. The nature of this gene encoding allows the innate immune response to easily detect microbial structures that are present in most organisms. Moreover, the innate immune system is the first line of protection as its detection mechanism is widely expressed with higher cell counts that rapidly neutralize any pathogenic agent found in the host cell environment [13].

The adaptive immune response system, however, evolves through mechanisms that are encoded by genes with a high specificity of antigenantibody binding for distinct microbial and environmental structures. The adaptive immune system from the onset generates low numbers of cells with high specificity for pathogens. Thus, any cell that detects pathogens must proliferate to counteract the microbial invasion. The adaptive response is thus a temporal expression that is triggered after the activation of the innate immune response [13]. It is known that the adaptive immune system exhibits high variability across individuals and that this variation could be partially ascribed to factors such as age, gender/sex, or seasonal variations [15-18].

\section{The Organizational Levels of the Human Immune} System: The human protective barrier system could be considered a three-level structure. The three levels consist of (1) anatomical and physiological barriers; (2) innate immunity; and (3) adaptive immunity. A system failure or breakdown of any one of these levels of protection will significantly impact and heighten infection risks. The first and foremost microbial defense systems in humans are anatomical 
and physiological barriers that provide the most critical first point of defense against pathogenic invasion. These underlying barriers include intact skin, vigorous mucociliary clearance mechanisms, low stomach $\mathrm{pH}$, and bacteriolytic lysozymes present in tears, saliva, and other fluid secretions [19].

Innate immunity serves as the second most important barrier system and complements the protection administered by both the anatomic and physiological barriers. The innate immune system is comprised of a limited arsenal of receptors that sense pathogenic attack. However, these receptors compensate for the deficit in their numbers by specifically targeting conserved microbial elements that have characteristic features of major pathogens. It is worthy to note that speed is a determining feature of the innate immune system, as, within seconds of a pathogenic invasion, the immune system is stimulated to initiate a protective inflammatory response. Furthermore, innate immunity is a precursor of the adaptive immune response [20].

It has been established that the adaptive immune system has a very diverse, randomly produced arsenal of receptors as compared to the limited number of microbial pathogens possessed by the innate immune system. Due to the wide spectrum of specificity of the adaptive immune system, its receptors can easily detect any antigen, thus making these receptors effective pathogen terminators. A graphical scheme of all three levels of the human immune defence system is shown in Figure 2.

\section{Anatomical and Physiological Barriers}

\section{Innate Immunity}
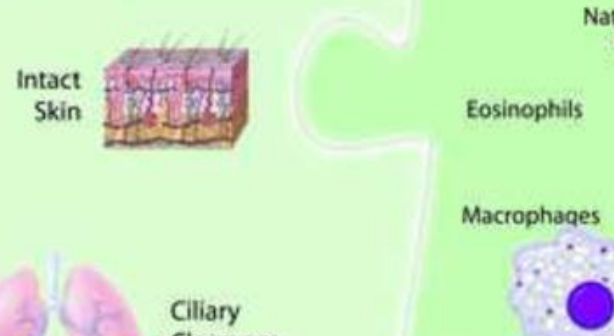

atural Killer

Cells

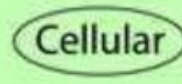

Mast Cells

\section{Ciliary}

Clearance
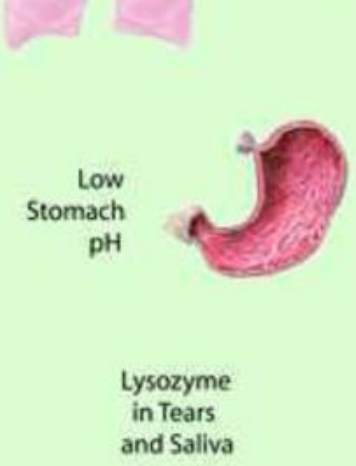

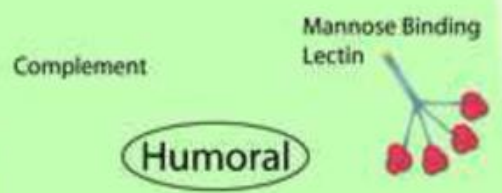

Natural Killer TCells
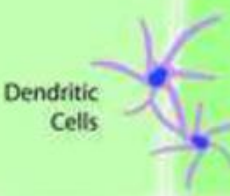

T cells Adaptive Immunity
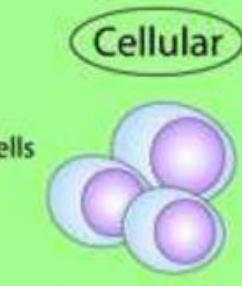

LPS Binding Protein

C-Reactive Protein

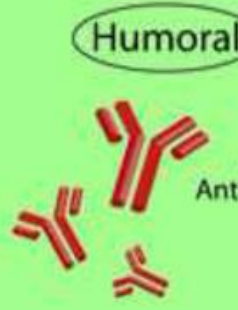

Antimicrobial Peptides

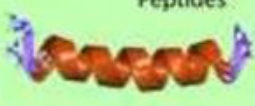

Figure 2. The three levels of the integrated human immune defense system [19]. 


\subsection{Characteristic Features of Innate and Adaptive Immunity}

The host's germ-line genes have an embedded functional property that acts as part of the immune defensive mechanism that is linked to the innate immune system. The defense system thus includes physical barriers, such as the epithelial cell layers that have closely linked cell-cell contacts, and mucous membranes that have a protective function in the respiratory, gastrointestinal, and genitourinary tracts. Another barrier is the epithelial cilia that help to remove foreign particles from the body [7-8]. Another innate response feature includes soluble proteins and bioactive minute molecules that are found in biological fluids (these are complement proteins, defensins, and ficolins) or that could be liberated from cells that are stimulated (involving cytokines that control cell function, chemokines that react with inflammatory leukocytes, lipid mediators of inflammation and bioactive amines and enzymes) [8].

Generally, innate immunity constitutes the first line of the host's defense system and exists naturally from birth. However, the defensive mechanism of the innate immune response does not intensify over time with exposure to pathogens. Instead, the innate immune response involves physical and chemical barriers such as hair, skin, cilia, mucous membranes, and other digestive enzymes. The innate immune response also includes internal defense systems such as phagocytic and natural killer cells, complement proteins as well as an inflammatory response system. The synergy from both physical and chemical barriers and that of the internal defenses holistically increase the innate immune response. The mechanism of action of innate immunity against pathogens is via two distinctive channels. The first channel is an elimination pathway through which toxic chemicals such as superoxide radicals and hydrogen peroxide are released by the phagocytes or through toxic proteins liberated by natural killer cells.

The second channel is pathogen destruction through the action of phagocytosis, which is enhanced through the process of coating the pathogenic agents with the host's complement protein system. This complement system comprises a complex network of plasma proteins that are activated in the presence of a pathogen. Phagocytosis is a process whereby a cell engulfs and eliminates cells, bacteria, and any other invasive pathogens [12]. The innate immune system's defense mechanism against pathogens does not rely on past exposure to specific pathogens. The innate immune response only supports immediate protection from pathogenic invasion and does not confer long-term protective immunity for the host [21].

The adaptive immune response, however, exhibits a unique and specific defensive mechanism against targeted pathogens. These responses are essentially based on the antigen-specific receptors expressed through antibodies that are produced on the surfaces of both the $T$ and $B$ lymphocytes. The $T$ lymphocytes are only positioned to detect antigens displayed on surfaces of cells; consequently, the infection of a cell by an invasive pathogen sends a 
signal to the T lymphocytes cell surface as a result of the peptide fragments obtained from the foreign agent. The transported peptide fragments found on the infected cell surface are thus presented in tandem with proteins known as a major histocompatibility complex (MHC). This protein complex is also referred to as the human leukocyte antigen (HLA). The reaction between the $\mathrm{MHC}$ and the pathogen-derived fragment enables the pathogen to be detected early by the T lymphocytes [12].

In comparison to the innate immune response, the adaptive immune response is completely different as its antigen-specific receptors are encoded by genes that are induced by somatic rearrangement of germ-line gene components to form an intact T cell receptor (TCR) and immunoglobulin (B cell antigen receptor; Ig) genes [8].

Unlike the innate immune response, the adaptive or acquired immune response has a more advanced memory recognition system, with an increased magnitude of response to any form of infection or pathogenic invasion. Thus, if an antigen is re-encountered or in the event of a re-infection, the defensive response is rapid and intensely stronger than the very first immune response that was triggered. Despite the immune system's effectiveness in detecting thousands of antigens, there is a high specificity of each lymphocyte for detecting and recognizing only one antigen. Thus, the population of specific lymphocytes for a unique or distinct antigen is very low [12]. Nevertheless, when the small number of lymphocytes encounter and recognize antigens, the lymphocytes firmly attach to the antigens which in effect results in cell division and the proliferation of new cells efficient enough to counteract the response from the antigen. This phenomenon is termed lymphocyte proliferation or lymphocyte expansion. The B lymphocytes proliferate and develop to form plasma cells, also known as antibody-producing cells, while the T lymphocytes differentiate into cytotoxic T lymphocytes that eliminate and destroy all virally infected cells. The $\mathrm{T}$ lymphocytes also regulate the operations of other cells known as helper T cells that are linked to this immune response [12]. Table 1 summarizes the distinction between the innate and acquired immune response.

Table 1. Conventional characteristics of innate versus acquired immunity.

\section{Immune system}

\section{Innate immunity \\ The reaction is non-specific \\ Infection leads to immediate maximal reaction}

Cellular and humoral components

No immunological memory

Does not create allergic reactions
Acquired (adaptive) immunity

Reaction occurs in detection of pathogens and antigens

Delay in time between infection and maximal reaction

Cellular and humoral components

The infection creates an immunological memory

Immediate hypersensitivity 
Major Histocompatibility Complex (MHC) Overview:

Major histocompatibility complexes (MHCs), also known as Human Leukocyte-Associated (HLA) antigens, are glycoproteins that are found on the surface of all nucleated cells of the body and are capable of binding peptide fragments of proteins that are produced intracellularly (Class $1 \mathrm{MHC}$ molecules) or have been digested by the cell and processed proteolytically (Class $2 \mathrm{MHC}$ molecules) [8]. MHCs are also a group of molecules that tend to impact and determine an organism's potential in accepting or rejecting transplanted tissues [12]. The operational scope of the T-cell receptor (TCR) is specific and limited only to detecting antigens transformed by $\mathrm{MHC}$ molecules whereas the $\mathrm{B}$-cell receptor (BCR) and other antibodies are efficient at detecting antigens without any intermediary element or molecule (the MHC sequencing consortium) [22-23]. The primary role of MHC molecules' binding action is to connect fragments of peptides obtained from pathogenic microbes. An important feature of the MHC process is that antigens are readily displayed on cell surfaces, and this enables easy detection by most T lymphocyte cells. This action triggers a kill step mechanism that is detrimental to pathogens, kills most virus-infected cells, and ultimately signals and induces macrophages that kill bacteria and other pathogens [24]. Along with these actions, B lymphocytes are concurrently stimulated to produce antibodies that neutralize or eliminate extracellular pathogens [25].

There are three important classes of $\mathrm{MHC}$ molecules, and each class has different peptide sources with corresponding specific binding characteristics that enhance efficiency. Class $1 \mathrm{MHC}$ molecules react or bind with peptides that are derived from pathogen proteins that are produced within the host cell cytosol and mostly originate from viruses or other bacteria. Class $2 \mathrm{MHC}$ molecules bind with peptides or glycoproteins originating from pathogens that have been phagocytosed and are expressed only on the surfaces of antigen-presenting cells (APCs) such as macrophages, dendritic cells and B lymphocytes $[12,26]$. Finally, Class $3 \mathrm{MHC}$ molecules bind with peptides that perform vital immune roles as well as complement the immune system by reacting with proteins linked to inflammatory activities. It is worth noting that Class 1 and $2 \mathrm{MHC}$ molecules are essential in mediating roles in antigen processing.

Class 1 and 2 MHC molecules encircle Class 3 $\mathrm{MHC}$ molecules, with the latter being vital in ensuring the increased production of molecules associated with immune function [27]. The $T$ cell receptors present on the surface of $\mathrm{T}$ lymphocytes have a rapid and sensitive signal detection system and can easily recognize the MHC peptide complex. The T lymphocytes that code or express CD8 detect Class 1 MHC molecules, while T lymphocytes that are linked to CD4 cells, recognize Class 2 MHC molecules. Therefore, intracellular pathogens induce cytotoxic T lymphocytes to neutralize and eliminate infected cells while extracellular pathogens induce the helper T cellmediated responses [12].

Discrimination of Self from Non-Self: The immune system has a sophisticated and efficient protective mechanism that can initiate destruction covering a wide spectrum of microbial cells and eliminate both toxic and allergenic substances. As a result, the 
immune response needs to be "self-aware" to prevent the self-destruction of host tissues. The phenomenon whereby the immune response evades self-destruction or damage to tissues of the host is termed self-tolerance [8]. A disruption of selftolerance or failure of this mechanism to work properly is detrimental and results in a wide array of autoimmune diseases. For this reason, it has been established that both the innate and the adaptive immune responses are gene coded and have internal mechanisms that prevent reactions with selfantigens. A classic example of this self-regulation is the $T$ cell repertoire of the immune system that has the potential to detect and recognize host cells infected by viruses and other bacteria. Thus, T cells have the mechanism to effectively differentiate foreign antigens from self-antigens and are, therefore, able to maintain a balance in self-tolerance in their operations [8].

The ability of the innate immune response to differentiate between self and non-self is generally linked to receptors that detect non-self-molecules or elements present in pathogens but absent in the host organism. These non-self-antigens are critical elements that coordinate the survival or virulence of microbial pathogens, therefore ensuring the integrity of their virulent state [28].

The acquired or adaptive immune response, on the other hand, generates an intensified specific defense system against invading pathogens and can uniquely detect and recognize them. Receptors produced from the $T$ and $B$ lymphocytes ( $T$ cell receptors and B cell receptors) are distinctly designed to detect any non-self-antigens. Thus, the adaptive immune response has developed the ability to discriminate self from non-self to prevent an anti-selfreaction and also has a sharp recognition system that aids in rapid pathogen detection and elimination processes [28].

The theory of 'extended self and non-self' credited to Janeway states that microbes are distinguished from self-molecules by an array of germ-line encoded receptors that detect molecular signatures that are present in the invading microorganism but absent in the host [29]. Microbial detection by the innate immune response relies on a system of receptors that recognize pathogenassociated molecular patterns (PAMPs) peculiar to most microbes and distinct from the self. Toll-like receptors (TLRs) are an example of this system of detection that structurally recognizes distinct molecules peculiar to many pathogens [30]. Innate immune responses are also sensitive enough to detect self-molecules that carry infected cells, and this phenomenon can be linked to the 'missing self' hypothesis proposed by Kärre et al. [31]. The involvement of inhibitory receptors in the operation of natural killer (NK) cells aids in distinguishing 'self' from 'missing self'. Moreover, infected cells coding MHC Class 1 molecules are highly resistant to NK cellmediated destruction when compared to virusinfected cells that can no longer code for MHC Class 1 molecule [31].

\section{Effector Cells of the Innate Immune System}

Macrophages: Macrophages work in tandem with monocytes as efficient phagocytes. Monocytes comprise $3-8 \%$ of circulating leukocytes that are present in the connective tissues of organs and ultimately produce macrophages and myeloid dendritic cells. Macrophages support the innate immune response and synthesize antigens courtesy of the MHC molecules that aid in the induction of the immune response mediated by T lymphocytes [24]. 
During inflammatory responses, macrophages behave like antigen-presenting cells (APCs) and activate both $\mathrm{T}$ and $\mathrm{L}$ lymphocytes, thus producing essential proinflammatory cytokines such as IL-1, IL6, IL-12, TNF- $\alpha$, and chemokines. Macrophages are also instrumental in producing reactive oxygen species (ROS) such as hydrogen peroxide and reactive nitrogen species (RNS) that are very effective against pathogenic invasion [24].

Dendritic Cells: Dendritic cells (DC) are essential modulators or intermediaries between the innate and adaptive immune response as they specialize in antigen attachment and the subsequent transfer of antigens to the lymphocyte cells. Dendritic cells are localized and are usually found in peripheral tissues such as the skin, liver, and intestines where they attach themselves to antigens [14]. Thus, dendritic cells promote activation that enables them to migrate to the lymph nodes where they transform and present protein antigen lipids to the T lymphocytes. Antigen attachment or capturing is a highly efficient characteristic feature of immature dendritic cells while mature dendritic cells are excellent antigen presenters. Antigens that are captured are transformed intracellularly with an effective binding to $\mathrm{MHC}$ molecules and consequently placed on cell surfaces [32].

Neutrophils: The most predominant defensive elements in the peripheral blood system are the neutrophils, which play a vital role at the onset of inflammatory reactions. These molecules are highly sensitive to chemotactic agents such as cleavage products of complement fractions ( $\mathrm{C} 3 \mathrm{a}$ and $\mathrm{C} 5 \mathrm{a}$ ) and other agents liberated by mast cells and basophils. Neutrophils are recruited by chemokines which promote the rapid migration of neutrophils from the vessels to the cells. IL- 8 is a classic example of a chemokine that is induced by bacterial products, complement proteins ( $\mathrm{C} 5 \mathrm{a})$, the immune complex (IC), chemokines, and cytokines [14].

Natural Killer Cells: The bone marrow has been credited as the reservoir for the constant production of natural killer cells (NKCs). Natural killer cells are generally generated from a common progenitor to the T lymphocytes which ranges between $5-20 \%$ of blood mononuclear cells [14]. NKCs function defensively in a non-specific way by detecting and neutralizing viruses and bacteria-infected cells as well as by the destruction of protozoa and tumour cells. Natural killer cells also work holistically with neutrophils and macrophages and induce dendritic cells as well as T and B lymphocytes [33].

Inflammation Overview: Inflammation is the term used to describe the immune system's mitigating response to dangerous stimuli such as microbial pathogens, injured cells, and toxic compounds plus the system's ability to eliminate undesirable effects while initiating the healing process [35]. Also, inflammation is defined as a biological response to disintegrated tissue homeostasis [36] and is thus the body's response to stimuli in the wake of an attack. Inflammation serves to protect the body's tissues and other vital organs from infections and injury. Generally, at the onset of acute inflammatory responses, intracellular activities help to reduce the extent of injury or infection. This phenomenon results in the stabilization of tissue homeostasis and resolves the acute inflammation condition. It is worthy to note that chronic inflammatory diseases are a result of uncontrolled acute inflammation conditions [37]. 
Some notable characteristics of tissue inflammation include redness, swelling, heat, pain, and a loss of tissue function as a result of responses to infection from the localized immune, vascular and inflammatory systems [38].

It is interesting to note that inflammation can be induced as a result of many factors attributed to pathogenic infection, injury to tissues as well as cardiac infarction. The cause or etiology of inflammation in many mammals can thus be classified under two sections, namely infectious factors and non-infectious factors. Most often than not, the major causative factor in inflammatory responses is infection via microbial invasion. Irrespective of this notion, it has also been established that injury or trauma (devoid of microbial infection) and exposure to foreign agents, pollutants, and irritants are potential activating agents of inflammation [36]. The inflammatory response is thus induced as a means of adapting or coping with the injured or malfunctioning tissues [39]. The advent of tissue injury automatically causes the body to initiate chemical signals that induce therapeutic mechanisms for the affected tissues [40]. The signals activated by the body lead to the induction of leukocyte chemotaxis. This induction is generally circulated to the damaged sites that synthesize cytokines, thereby inducing inflammatory responses [41].

Inflammatory Cytokines: Cytokines are essential protein molecules that are synthesized by specific immune cells that include monocytes, macrophages, and lymphocytes. Cytokines are known as a class of signalling molecules that serve as mediators and regulators of immunity, inflammation, and hematopoiesis [40]. The facilitation and inhibition of inflammation conditions are coordinated by both pro- and anti-inflammatory cytokines. Inflammatory cytokines are categorized as Interleukins (ILs), colonystimulating factors (CSF), Interferons (IFNs), Tumor Necrosis Factors (TNFs), Transforming Growth Factor (TGFs), and chemokines that are all generally synthesized by the immune cells and, in effect, stimulate leukocytes to respond to the infection or injury site [42]. The regulation of inflammation and the immune response to an infection is significantly coordinated by cytokines that operate through a complex network of interactions. It is worth noting that excessive production of inflammatory cytokines can result in tissue damage, organ failure, and, in some cases, death. This serious immune reaction is referred to as a 'cytokine storm' [43-44].

\section{Inflammation Response Mechanism: Many pathways}

such as the nuclear factor kappa-light-chain-enhancer of activated $B$ cells (NF-KB) pathway, mitogenactivated protein kinase (MAPK) pathway, and the Janus Kinase/ Signal Transducer and Activator of Transcription (JAK-STAT) pathway are signalled during an inflammatory response to regulate the levels of cell or tissue inflammation that occur in the blood system [45]. It is well-known that the pathogenesis of many chronic and devastating diseases has been linked to inflammation. Some of the diseases of concern are diabetes, cardiovascular and bowel disease, arthritis, and cancer [46]. Although the inflammatory response is dependent on the initial stimulus and its location in the body, the response mechanism is always the same and includes the following actions: 1) detection of harmful stimuli by cell surface pattern receptors; 2) activation of inflammatory pathways; 3 ) liberation of inflammatory markers; and 4) assembling of inflammatory cells [40]. 
The first and foremost step in the inflammatory response mechanism entails the detection and recognition of damage or pathogenic infection. The detection and recognition of pathogenic infections are enhanced by pathogen-associated molecular patterns (PAMPs) that uniquely sense and recognize molecules produced by pathogens. Another important inflammatory response mechanism is linked to damage-associated molecular patterns (DAMPS) also known as alarmins. DAMPS are endogenous elements that flag damaged or injured cells and are generally recognized by the innate immune system. An essential benefit derived from this signal detection is that unintentional host cell targets are significantly reduced. In comparison to the adaptive immune system, the innate immune system is not capable of differentiating between pathogenic strains and whether or not such strains pose a threat or are virulent to the host [47].

Most transmembrane TLRs and intracellular nucleotide oligomerization domains (NOD) in conjunction with leucine-rich-repeats contain critical receptors that are known collectively as NOD-like receptors (NLRs). These NOD-like receptors are thus capable of detecting many damaged and injured cells by their germ-line encoded receptors. NOD-like receptors and leucine-rich repeats are a group of specialized intracellular proteins that perform a vital role in the regulation of the host innate immune response $[30,48]$. Upon detection of ligands, TLRs immediately activate general signalling pathways that propel the activation of NF-KB (Nuclear Factor kappalight-chain-enhancer of activated B cells). NF-KB is a transcription factor present in all cells and is always activated and bound to an inhibitor protein known as IXB [49]. NF-KB is liberated from IXB upon transmission of the transduction signal and enters the nucleus with an upregulation of transcription by attachment to target genes.

The extensive numbers of generated DAMPs thus activate intracellular NLRs, which in effect notifies the immune system to respond to cell injury and to ultimately provide a proximate pathway for detecting potential toxins or pathogenic invasion [50]. The third phase of the inflammatory mechanism involves the process of gene transcription and translation that leads to the synthesis of proinflammatory cytokines such as Interleukin-1-beta (IL-1ß), IL-6, Tumor Necrosis Factor-alpha (TNF- $\alpha$ ), among others. These cytokines along with chemokines and other molecules ensure the assembling of effector cells such as monocytes and neutrophils at the affected site of concern. The function of neutrophils is to rapidly generate a cytotoxic environment through the release of noxious chemicals produced from cytoplasmic granules in a process termed degranulation. Notable among the liberated toxic chemicals are highly reactive oxygen species (ROS) and reactive nitrogen species (RNS) as well as a varied number of proteinases [51]. The toxic chemicals that are released during this process are very lethal to both pathogens and hosts and could induce tissue liquefaction to impede microbial metastasis [52]. The overall impact produced by this array of interactions results in local inflammation signs that are characterized by swelling, pain, redness, and ultimately loss of function.

The final phase of the inflammation process is its resolution which is vital in reducing extensive damage to the host cells and tissues [53]. A well-structured resolution system is activated a few hours after the initial inflammatory response by tissue-resident macrophages. In the presence of acute inflammation, macrophages initially generate pro-inflammatory 
prostaglandins and leukotrienes but, the macrophages are quickly transformed into lipoxins thus creating a barrier that prevents further assembling of neutrophils and ultimately stimulates monocytes that provide therapeutic comfort [51].

Influence of Aging on the Immune Response: The ageing process is a fundamental stage in the human life cycle during which the physiological state of the organism is significantly impacted the molecular, systemic, and cellular levels with a direct impact on overall functionality. Ageing, therefore, increases the body's susceptibility to several chronic disease conditions [54], and age-related physiological changes play a role in the immune response of the human body. There is, therefore, a direct relationship between immune function and ageing which affects the mechanisms of both the innate and the adaptive immune response systems. The immune changes that occur during ageing are known to be very complex, and this process is generally referred to as immunosenescence. By definition, immunosenescence is the dysregulated state of immune function in the elderly that is a result of ageing, and which poses a higher risk of infection and susceptibility to autoimmune diseases and cancer. It is noteworthy that the ageing process is not only responsible for decreasing the functionality of the immune system, but also affects immune system modulation.

Although there is a general decline in many aspects of the immune function with ageing, some aspects continue to remain stable while some become overreactive. Immunosenescence can, thus be inferred and explained in the context of dysregulation of the immune system rather than a complete deterioration of the immune system [54].
The onset of immunosenescence affects both the innate and adaptive immune systems however, the adaptive immune system is greatly affected by the innate immune system.

There are myriads of factors and mechanisms that are linked to immunosenescence including bone marrow defects (results in changes in the constituents of both lymphoid and myeloid cells transported to the periphery), thymus involution (reduces the synthesis of new T cells), and impediment in the development, homeostasis, and movement of peripheral lymphocytes [55]. Another intrinsic factor linked to immunosenescence is changes in DNA methylation that occur in the immune cell system and which results in a reduced level of genomic methylcytosine across all major tissues. The DNA demethylation process in the elderly has been confirmed to be very notable in the brain, liver, heart, spleen, small intestine mucosa as well as in T lymphocytes. These age-dependent changes in DNA methylation have been confirmed as a contributing factor to $T$ senescence [56]. Extrinsic factors of concern are also linked to health-related attitudes and exposure to chronic stress that can significantly worsen the process of immunosenescence [57].

Ageing thus plays a significant role in shaping the immune profile of the individual [58]. Older people are more prone to viral infections than younger people, which could be due to the less wellfunctioning immune system that accompanies ageing. In the publication by Suchard [59], she notes that immune ageing is driven primarily by changes in $T$ cell-mediated immunity. There are fewer antigenic $T$ cells in the peripheral blood of older individuals than in younger individuals, and the reduced memory of Tcells demonstrates poorer functional ability to respond to pathogens. For example, Hattaf and Yousfi 
[60] reported on a mathematical model that incorporates the two modes of viral transmission (one mode by virus-to-cell infection, and the other one by direct cell-to-cell transmission) and takes into account the role of the adaptive immune response in HIV infection. They reported the importance of the adaptive immune responses of cytotoxic $\mathrm{T}$ lymphocytes (CTLs) and antibodies in the control of HIV infection.

The thymic involution and the antigenic stress during ageing cause the small number of thymic emigrants of new naive T cells in the elderly. Naive T cells are vital components of the immune system that strengthens and defends the human system from new unrecognized diseases and infections [61]. Concerning $T$ cell sub-populations during the ageing process, the decrease in naive T cells and the increase in memory $\mathrm{T}$ cells are considered to be the primary changes related to changes in the adaptive immune system. This may help to account for both the increased susceptibility to infections and the reduced efficacy of vaccines in the elderly [62].

Caruso et al. [63] reported that B-cell division is also affected by ageing individuals. T-independent functions of B cells, such as polysaccharide responses that are crucial for antibacterial protection, are also lacking in later life. Also, there is evidence to suggest that $B$ cells are important antigens that may be key regulators of T cell development. Consequently, some deficiencies in $T$ cell function may be due to insufficient assistance from B cells.

Aguirre-Gamboa et al. [58]analyzed the determinants of variation in T and B cell counts and Immunoglobin (Ig) levels by testing the association between immune traits and age as one of the nonheritable factors. According to their findings, ageing was significantly associated with a decrease in lymphoid immune cell levels (naïve T cells, B cell subsets) and a concomitant increase in myeloid immune cell levels of granulocytes, pro-inflammatory non-conventional monocytes (CD14++CD16+), intermediate monocytes (CD14+CD16+) and levels of proliferating CD4+ regulatory T cells.

Valiathan et al. [64] studied the changes in different immunological processes during ageing and determined the changes occurring in infants (1 month to 1 year), children (1 year to 6 years), adolescents (12 years to 18 years), adults ( 21 years to $50)$ and the elderly (70 years to 92 years) with regard to blood count and lymphocyte subsets and the differences in cytokines and growth factor levels between adults and the elderly. Their results revealed progressive declines in the percentage of total lymphocytes and absolute numbers of $\mathrm{T}$ and $\mathrm{B}$ cells. The percentages of $\mathrm{T}$ cells increased with age from infant to adulthood and then declined. Proinflammatory cytokines TNF-a and IL-6 were higher in elderly people compared to adults. The elderly group had significantly higher levels of monocyte chemoattractant protein-1 (MCP-1) and lower levels of epidermal growth factor (EGF) compared to adults. All of these results confirmed the age-related changes in lymphocyte subpopulations.

\section{Impact of Aging on the Cells of the Innate Immune}

System: The ageing process has a significant impact on reducing the total functionality of the innate immune system. The cells of the innate immune system include neutrophils, macrophages, dendritic cells, and natural killer cells. The various alterations that occur in the individual cells will be briefly reviewed. 
Neutrophils and Dendritic Cells: Neutrophils generally have reduced functionality in elderly people. Some of the notable functions that are impacted include chemotaxis, phagocytosis, synthesis of free radical, as well as susceptibility to apoptosis [65]. There is also a reduced functionality in cell surface receptors such as TLRs, reduced synthesis of cytokine, and ultimately decreased expression levels of MHC Class 2 molecules. Such weakened functional activity in these aforementioned cells and molecules can have negative-to-dire consequences in preventing infections and globally breaking down the immune defense system of the elderly.

Dendritic cells (DCs) also play an important role in the immune response system of the elderly. The proliferation and activation of T cells are impeded as the functionality of DCs becomes attenuated due to ageing. This impaired functionality affects the distribution and rapid movement of DCs within the cell matrix, their antigen-processing ability and hindered synthesis of cytokines. The reduced efficiency of DCs thus implies a weakened defense system against pathogens and other sources of infections [56].

\section{Monocytes, Macrophages, and Natural Killer Cells:}

The level of blood monocytes is directly proportional as it considerably increases with age and does not decline in older age; this situation is however not the same in the case of the percentage of macrophages in the bone marrow. The macrophages in the bone marrow steadily decline over time and especially in elderly individuals between 80 to 100 years of age. The decline in macrophages in the bone marrow has been attributed to an increased level of apoptosis and decreased cellularity. Moreover, there is also a decrease in the expression of MHC Class 2 molecules in macrophages that is ultimately due to ageing. The overall efficiency of macrophages is adversely affected as their phagocytic actions become significantly reduced with age progression. This adverse impact also results in decreased levels of synthesis of reactive oxygen intermediates such as $\mathrm{NO} 2$ and $\mathrm{H} 2 \mathrm{O} 2$, and consequently decreased levels of macrophage-derived cytokines (TNF-a and IL-1) [66].

Several studies have reported an exponential increase in the total number of natural killer (NK) cells associated with an increase in age in many healthy elderly individuals. However, it was also established that the functionality of NK cells declines with age, resulting in poor functionality. The generation of cytokines and chemokines such as MIP1a and IL-8 also decreased significantly. The global increase in NK cells is thus considered to partially compensate for the concomitant decrease in the functionality of these cells [54].

\section{Impact of Aging on the Cells of the Adaptive Immune}

System: The adaptive immune system is generally linked to the synthesis of a diverse repertoire of antigen-specific receptors on the $\mathrm{T}$ and $\mathrm{B}$ lymphocytes and consequently activates these receptors. These specialized receptors are synthesized through the somatic recombination of encoding gene sequences [67]. However, B lymphocytes are significantly impacted and decrease with age. Thus, the elderly have a decreased response from $B$ lymphocytes in the event of pathogenic invasion or infection due to defective production of antibodies from these lymphocytes [68].

T lymphocytes are expressed in two significant forms that are the CD4 and CD8 recognizing antigens and are generally expressed in the context of the $\mathrm{MHC}$ molecules. The progression in one's age has a 
significant impact on the functionality of T cells as well as the global immune response to infections and pathogens. A decrease in T cell levels has been linked to the regression of the thymus due to the ageing process [69]. This change in the functionality of T cells thus increases the risk of infections, autoimmune diseases as well as cancer in the elderly [70]. Another factor that impedes the functionality of the T lymphocytes is oxidative stress and chronic antigenic load which increases pro-inflammatory conditions that lead to induced cell death [71].

\section{Influence of Biological Sex on the Immune Response}

and COVID-19: According to Holdcroft [72], sex and gender are defined differently in the field of medicine. Sex is defined as the biological and genetic difference between the $X X$ and $X Y$ chromosomes while gender is associated with the psychosocial, cultural, and economic differences that exist between males and females. However, it is essential not to separate sex and gender concerning immunity as both elements work in tandem and play a vital function in immunological dimorphism [72]. The integrated immune systems of males and females are fully functional due to the collaboration between the different sex hormones, genetic ( $X X$ and $X Y)$ chromosomes as well as impact from the environment [76]. The immune system is an essential component of all mammals. However, it does not function in isolation but rather works in concert with coordinated responses from a variety of endogenous and exogenous factors and modulators. The response to stimuli and the overall regulation of the immune systems of both males and females is largely determined by the differences in sex. It is evident from various studies that females possess a more robust innate, cell-mediated, and humoral immune response to antigenic molecules than do males [75]. This phenomenon in females can thus limit the pathogenic load and increase the elimination of pathogens, which consequently hastens the immune response in immune-related pathologies such as autoimmune or inflammatory diseases [76].

Research has confirmed varying differences in the innate recognition and response to viruses which generally impacts the adaptive immunity between males and females during the onset of viral infections. Males generally possess lesser antiviral, inflammatory, and humoral immune response than females during viral infections and are thus prone to a higher risk of a viral infection such as COVID-19 [77]. This assertion is buttressed by evidence of sex differences in patients severely infected by COVID-19 in China, whereby the rate of mortalities and hospital admissions were higher than normal among males than in females [78].

A study also conducted by Meng et al. [79] on 168 patients in Wuhan, China diagnosed with severe COVID-19, confirmed that men were significantly at risk to remain confined in medical facilities and eventually being hospitalized, thus leading to a high mortality rate. This was, however, not the case for women in the study who were more frequently discharged from the hospital. This discrepancy between the males and the females were most evident among individuals aged 60 years and above. 
It was also observed that between these two sexes, the ratio of the neutrophil-to-lymphocytes in male COVID-19 patients during hospitalization and after death were extensively higher than in females and patients that were discharged. Similarly, the concentration of the serum C-reactive protein, lactate dehydrogenase, blood urea nitrogen, serum creatinine, and aspartate aminotransferase was twice higher in males than females COVID-19 patients who died than in patients discharged [79].

Also, in another jurisdiction of South Korea, whereby widespread community testing of COVID-19 was pronounced, it was observed that females represented less than $60 \%$ of the population that tested positive for COVID-19. This thus inferred that although females were prone to infection by COVID19 they consistently had a lower rate of fatality cases [78]. In the United States for instance, although the rate of diagnosis was almost the same in both males and females, it was however evident that males had 1.5 times higher mortality rates than females. Consequently, a male bias has been reported in COVID-19 mortality rates in 37 of the 38 countries that have furnished sex-linked data on COVID-19 infections. This data thus confirmed that the case fatality rate in the average male in almost all the 38 countries was 1.7 times higher than the average female case fatality rate [78].

Along with age, sex contributes significantly to the formation of immune profile and immune responses, as well as to the differences in the pathogenesis of infectious diseases in men and women [80]. Aguirre-Gamboa et al. [58] in their study on the effect of sex on the different B cell and Ig levels confirmed a significant increase in the following; mature B cell subsets, IgM-only B cells, plasmablast B cells, proliferating and memory (CD45RA) Treg cells, NK cell subsets, and IgM serum levels in women. There were also increased levels of effector and effector memory T cells and a reduced level of IgG4 and IgA in men. These variations could be due to the differences in biological factors (i.e., sex differences, such as genetic and epigenetic factors, sex hormones) and to psychosocial factors (i.e., gender differences) among men and women $[58,81]$.

The discrepancy and differences in the functionality of the immune system in male and female sexes can lead to several health and lifespan disparities. The role of sex in immune functionality is thus quite vital and contributes to what is referred to as sexual dimorphism which connotes females to have a more resistant immune response than that of men. Although males and females possess the same type of immune cells, the responses exerted by each individual against the invasion of bacteria, viruses, and allergens are uniquely different. Research has confirmed females to be at lower risk of microbial infections due to their immune responses having a prolonged humoral, much stronger, and cellmediated against infections $[75,82]$. Moreover, at the molecular level, the immune response of females is stronger than that of males as a result of increased levels of Immunoglobins IgM and IgG [73]. Females also possess an extensive higher innate immune response system than males which enables them to be more resistant to infections. However, females are 
more susceptible to immune-mediated diseases such as autoimmune disorders and inflammatory diseases and this could be attributed to the $\mathrm{X}$ chromosome in females that are associated with many genes that work about the immune system [76,83].

On the other hand, Zeng et al. [84] compared the differences of the SARS-CoV-2 IgG antibody between male and female patients. They reported that the concentration of IgG antibody in mild, general, and recovering patients showed no difference between male and female patients while in severe status, compared with male patients, more female patients were having a relatively high concentration of serum SARS-CoV-2 IgG antibody. Moreover, the generation of IgG antibody in female patients was stronger than in male patients in the disease early phase.

In another study, Nyenhuis et al. [85] studied the association of race with differences in airway inflammation in asthma of African-Americans and Caucasians treated or not treated with ICS (ICS+ and ICS-). The results demonstrated that AfricanAmericans exhibited greater eosinophilic airway inflammation, which may explain the greater asthma burden in this population. The authors identified a number of race-related differences in clinical characteristics as African-Americans had lower lung function (FEV1\%), a higher BMI and total serum IgE level and were more likely to have uncontrolled asthma. It was concluded that the increased risk of eosinophilic airway inflammation in AfricanAmericans on ICS may be due to higher rates of corticosteroid insensitivity and reduced cellular sensitivity to corticosteroids in African-Americans with asthma.

Hormonal Influence on Immunity: Three important steroid hormones significantly influence the various effector cells of the immune system through a coordinated modulation process. These hormones are estrogen, progesterone, and testosterone, and they work closely together by binding to specific receptors that are both nuclear and non-nuclear [73]. Estrogen (E) attaches to estrogen receptors (ER) that help to promote direct and indirect immune responses. The direct immune response is coordinated by a linkage between estrogen and the estrogen receptor (E/ER) to form a complex that binds to estrogen response elements (ERE) within the promoting genes. An indirect immune response, however, relates to the linkage between the E/ER complex with an unrelated transcription factor that aids in functional modulation [73]. In summary, hormones impact the immune system as immune responses are either upregulated or downregulated. Estrogen has been confirmed to efficiently increase immune responses while progesterone and androgens considerably decrease immune responses [73].

Estrogen has also been credited with functional modulation of B cells, thus enhancing the response of Th2 cells [86]. Moreover, estrogen enhances physiological functions that are coordinated by the ERs and are expressed in the gut epithelial cells, the brain, lymphoid tissues, and the immune cells as well [87]. T cells are greatly stimulated by the increased 
expression of CCR5 which is a chemokine receptor. However, testosterone, an androgen, has been characterized as an immunosuppressive hormone. Despite the negative effect of testosterone, it can increase the response of Th1 cells and stimulate CD8 cells while downregulating the response of natural killer cells and tumour necrosis factor-alpha (TNF $\alpha)$ and heightening the generation of anti-inflammatory IL-10 [88].

\section{Genetic Influence on Immunity: Sexual} immunological dimorphism relates to the different expression of the $X$ and $Y$ genes and their immune response impact in the different sexes. More than 1400 genes have been mapped on the $\mathrm{X}$ chromosome while the $\mathrm{Y}$ chromosome has over 200 genes. Moreover, the $\mathrm{X}$ chromosome has many genes that code for proteins linked with immune functions. This discrepancy between the two chromosomes thus accounts for a greater immune response in females than in males. Some of the proteins that these immune-related genes code for are TLR7 and TLR8, $\gamma$ chain subunits common to the receptors for IL-2, IL-4, IL-7, IL-9, IL-15, IL-21 and transcriptional factors such as Foxp3 [89]. Moreover, females have a greater expression of TLR7 than males do. It is also noteworthy that the expression of $X$ linked genes may be impacted by X-linked micro-RNAs (miRNAs) which controls the expression of the mRNA gene posttranscriptionally. This miRNA gene found on the $X$ chromosome is also known to be a key modulator in the maintenance of immunological homeostasis and could be linked to the sex-specific development of autoimmune diseases [90].
Influence of Environmental Factors and Seasonal Variations on the Immune System: There is considerable interest in the extent to which the environment and genetic factors affect the homeostasis of human immune cells as well. Research has shown that there may be some seasonal variations in immune profiles, and this assertion was confirmed in a study conducted by Aguirre-Gamboa et al. [58] using healthy human volunteers from the Human Functional Genomics Project. It was observed that the B cell subpopulations, as well as IgG, IgG1, and IgG4 levels were higher during the winter. Treg, $\mathrm{NK}(\mathrm{T})$, and classical monocytes (CD14++CD16-) were also significantly higher in winter, while granulocytes, proliferating CD8+ T cells and CD4+ effector memory cells showed a higher peak during the summer months. Results obtained from the study thus validates the vital role that varying seasons could generally play in modulating and affecting the cellular and humoral immune response against many viral infections and allergies. The seasonal variation hence poses the high risks of allergies and contracting viral infections such as COVID-19 if the immune response system is compromised [58]. There is an association between temperature and infected people among the spreading factors of the disease. An increase in temperature caused a decrease in the number of infected cases. Meanwhile, a decrease in temperature after the temperature shock was associated with an increase in the number of cases, which tended to zero overall [91].

Aguirre-Gamboa et al., [58] were also able to prove in their study that environmental and genetic factors had an impact on the homeostasis of the human immune system. This was confirmed in their 
findings, whereby the level of T cell immunity was strongly linked to genetic factors, whereas the level of immunity of the B cells was largely linked to environmental factors. Mangino et al. [92] analyzed the immune phenotypes of adult female twins and reported that the adaptive immune traits were more affected by genetics, whereas innate immune traits were more affected by the environment. According to the authors' findings, the majority (76\%) of these traits showed a predominantly heritable influence, whereas $24 \%$ were mostly influenced by the environment. Environmental factors such as physical activity, diet, infections, or microbiota influence the immune homeostasis for monocytes, B1 cells, $\mathrm{\gamma} \delta \mathrm{T}$ cells, and NKT cells, whereas dendritic cells, B2 cells, $\mathrm{CD} 4+\mathrm{T}$, and $\mathrm{CD} 8+\mathrm{T}$ cells are more influenced by genetics [93].

Influence of Physical Activity or Exercise on the Immune System and COVID-19: Physical activity as reported by many studies has been proven to stimulate positive, considerable physiological changes in the immune system [94]. Although the term 'physical activity' is often construed to be synonymous with 'exercise' as both have similar elements, there exist some differences. Physical activity can be defined as any movement of the body that is produced by skeletal muscular actions and an increase in total energy expenditure. Exercise, on the other hand, is defined as any 'planned, structured, and repetitive physical activity' [94]. Another term of importance is physical fitness, which also relates to the ability to perform physical activity and the resultant benefits while entailing a broad scope of physiological and psychological qualities. The immune system has a coordinating functional mechanism that is enhanced through physical activity or exercise. It is noteworthy that the intensity of physical activity performed has an overall impact on the body's metabolism, as well as on the total amount of energy expended.

It is well known that regular physical activity enhances the effectiveness of the immune system, therefore it could positively affect the severity of SARS-CoV-2 infection [95]. Physical exercise has been confirmed as a preventive activity for viral infections such as COVID-19. It is thus paramount to adopt habits geared towards physical exercises as this increases immunity against COVID-19 which considerably causes heart and kidney damage, lung damage, and pneumonia in humans [96-97]. The importance of physical activity cannot be overemphasized as it ensures and increases immune responses and builds a formidable immune system that counteracts all viral infections. Physical activity also enhances cardiovascular functionality, protective effects against cellular stress, and promotes coagulation and fibrinolytic homeostasis [18, 98]. Maintaining a regular exercise routine is considered as a key strategy for physical and mental health during a forced rest period like the current coronavirus emergency as the lack of physical activity leads to a decrease in well-being, accompanied by increased anxiety, delayed and poorer quality sleep [99]. Physical exercises have also been reported to increase the activity of the $\mathrm{T}$ and $\mathrm{B}$ lymphocytes thereby supporting an enhanced immune system. This is confirmed by the release of interleukin-15 (IL$15)$ in muscle fibres after a session of physical activity. IL-15 is thus a vital protein required for the 
proliferation and activation of the $\mathrm{T}$ and natural killer cells that help to boost the body's defenses against viral infections such as COVID-19 [97]. Systematic and frequent physical activities other than a sedentary lifestyle have been proposed and recommended by scientific research to prevent several chronic diseases and viral infections like COVID-19 [100]. Physical activity is, therefore, an indispensable factor that stimulates the immune system in the fight against emerging viral infections like COVID-19 [97].

Intensive training such as endurance training has been linked to immunosuppression in many studies. Moderate physical activity, on the other hand, is reported to be a stimulator of several immune response functions. This assertion has been confirmed by studies that have shown the association between physical activity and upper respiratory tract infections (URTI). Regular physical activity is thus thought to be inversely linked with URTI [94]. The notion of intense workouts having an adverse effect on the immune system has been corroborated by many studies conducted on athletes and sportspeople. Athletes and sportspeople performing high-intensity physical activities are prone to an alltime increased risk of infections due to impaired immunity [101]. This phenomenon could thus be linked to the hypothesis of the 'inverted J curve' with exercise immunology. This hypothesis alludes to an increased susceptibility to infection and diseases in sedentary and overly trained athletes as compared to athletes who train regularly and moderately [94].

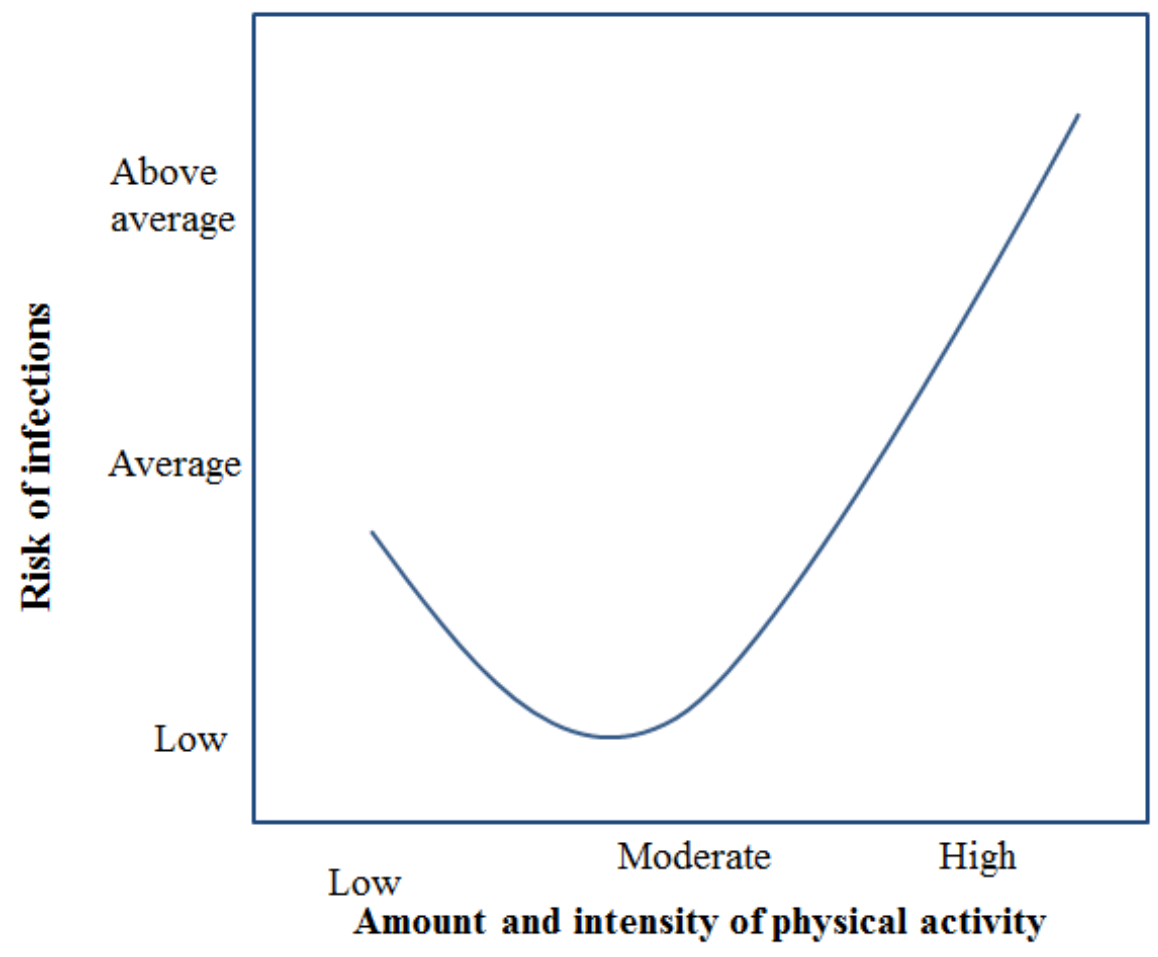

Figure 3. "J"-curve hypothesis of association between the amount and intensity of exercise and susceptibility to infection 
The effects of physical activity on the immune system have been widely hypothesized by scientific research. However, the widely accepted hypothesis that has been linked to immune functionality is the Jcurve hypothesis. This hypothesis reveals an association between the intensity of exercise and the susceptibility to infection (Figure 3) [102]. The factors related to the J-curve hypothesis include the type of physical activity, the duration and the intensity of the exercise performed [94]. The hypothesis was formulated based on a cross-sectional analysis of a mixed cohort of marathon runners, sedentary men and women in addition to longitudinal studies performed on athletes and non-athletes. The study elucidated the impact of exercise on immunity by confirming an enhanced immune function as a result of moderate exercise above sedentary levels whereas the excessive and prolonged duration of exercise leads to immune function impairment [103].

Immune Function Over the Life Course: The development of the immune system in early life is influenced by both feeding practices and environmental exposure. Breastfeeding provides further passive immunity for the infant via the transfer of antibodies and cytokines. Breast milk components can also stimulate maturation of the gutassociated lymphoid tissue, as breast milk is known to be rich in bifidogenic oligosaccharides and contains its unique microbiota. Human milk oligosaccharides (HMOs) are synthesized from lactose in the mammary glands. The specific HMO profile will vary between individuals and across contexts and changes over the time course of lactation [104]. HMOs have been found to confer health benefits to infants by inhibiting the adhesion of microorganisms to the intestinal mucosa, enhancing the production of short-chain fatty acids by bacteria within the microbiome, and inhibiting inflammation [105]. Other active immune components of breast milk are likely to be involved in immune system maturation. For example, studies have shown that epidermal growth factor, fibroblast growth factor 21, and transforming growth factor- $\beta 2$ can change lymphocyte phenotypes in new-born rats when provided as supplements by oral gavage [106].

Nutritional Influence on the Immune System: Nutrition plays a vital role in the immune system. Low intake of energy, macronutrients and/ or micronutrients will impair the immune system through suppression of immune functions needed to protect the host against pathogens [12]. Individuals at the highest risk include infants and children whose immune system has not fully developed, and the elderly and those with underlying conditions that may compromise immune function. Nutrition is fundamental to supporting immunity. The immune system is the body's defense against disease and infection, and it has long been established that important factors influencing the function of the immune system include stress levels, sleep and nutrition. Macronutrients such as proteins, carbohydrates and fats, as well as micronutrients (vitamins and minerals), interact with immune cells systemically in the blood, regional lymph nodes and in the specialized gastrointestinal immune system. Carbohydrate $(\mathrm{CHO})$ is an important fuel cell for immune system support as adequate intake of $\mathrm{CHO}$ reduces the severity of infection. Protein is also crucial to regulating the immune system, especially for building and repairing body tissue and fighting viral and bacterial infections. In addition, amino acids provide an important energy source for many cell types including those involved in immune responses. 
For example, glutamine serves as a precursor for nucleotide synthesis and is particularly relevant for rapidly dividing cells such as the immune cells during an immune response. Some amino acids such as arginine, glutamine, taurine and sulfur- containing amino acids are related to the ability to control various diseases [107]. The human diet serves as a source of a variety of key PUFAs, including the essential fatty acids, linoleic acid $(18,2 n-6)$, alphalinolenic acid $(18,3 n-3)$, as well as their longer chain and more highly unsaturated products arachidonic acid (arachidonic acids (AA); 20, 4n-6), eicosapentaenoic acid (eicosapentanoic acid (EPA; 20, 5n-3)) and docosahexaenoic acid (docosapentanoic acid (DHA) 22, 6n-3). Kumar et al. [108] studied the role of polyunsaturated fatty acids (PUFA) in improving immune function and the reduction of systemic inflammation via the modulation of pattern recognition receptors (PRR) on immune cells. Extensive research on the use of bioactive lipids such as eicosapentaenoic acid (EPA) and docosahexaenoic acid (DHA) and their metabolites has illustrated the importance of thes pro-resolving lipid mediators in modulating signalling through PRRs.

Nutrients needed for the immune system to function optimally and efficiently include essential amino acids and fatty acids, such as linoleic acid, vitamins $A, C, D, E$ and $B 6, B 9$ and $B 12$ along with minerals zinc, copper, iron and selenium [12]. A deficiency in one or more of the above nutrients may impair the immune system. However, once the deficiency is corrected, the immune function is restored and the ability to fight infection improves. Conversely, excessive supplementation may result in impairment of the immune system. - Vitamin E - fatsoluble antioxidant vitamin: protects cell membrane lipids from peroxidation [12]. Supplementation in animal studies found an "enhancement of antibody production, lymphocyte proliferation, natural killer cell activity and macrophage phagocytosis" [12]. Results from the studies suggest supplementation of vitamin $\mathrm{E}$ above the normal dietary intake may enhance immune function and improve resistance against viral infections such as influenza or COVID-19.

Vitamin D originates from ultraviolet B (UVB) radiation exposure of 7-dehydrocholesterol (7-DHC) in the epidermis of the skin, where vitamin $D$ is transformed into the circulating precursor cholecalciferol. Vitamin D supplementation has been shown to have protective effects against respiratory tract infections. For example, the optimal level of vitamin $D$ supplementation in order to maintain the circulating $25(\mathrm{OH}) \mathrm{D}$ is considered to be 75-125 $\mathrm{nmol} / \mathrm{L}$; consquently, people who are at higher risk of vitamin D deficiency during this global pandemic should consider taking recommended amounts of vitamin D [109]. Vitamin D is linked to a range of COVID-19 risk factors such as advanced age, obesity, male sex, and hypertension. It has been reported that vitamin D enhances innate cellular immunity through stimulation of expression of antimicrobial peptides [110]. It has been suggested that adequate vitamin D levels may help to protect the respiratory epithelium from pathogenic invasion, thereby decreasing the risk of infection. In addition, vitamin D is able to modulate the adaptive immune response by suppressing $\mathrm{T}$ helper type-1 (Th1) cell function and decreasing the production of pro-inflammatory cytokines IL-2 and interferon-gamma (INF- $\gamma)$. COVID-19 patients have been repeatedly shown to have lower levels of vitamin D; therefore, supplementation with vitamin D is recommended in order to boost immunity against COVID-19 and reduce mortality [111]. 
Trace minerals: A zinc deficiency is related to a decrease in natural killer cell activity. Repletion of zinc to correct the deficiency will restore the natural killer cell activity, raise CD4+:CD8+, increase lymphocyte proliferation, IL-2 production and the DTH (delayedtype hypersensitivity) response. Human studies have found that zinc deficiency lowered IL-2, IFNg and TNFa but did not affect IL-4, IL-6, IL-10 or IL-1b. Additionally, low zinc levels may predict the development of respiratory tract infections, with several studies supporting supplementation to reduce respiratory illness. High intake of zinc will decrease copper absorption and may lead to a copper deficiency thus impairing immune function [12]. Copper (Cu) deficiency in humans was associated with very diverse clinical symptoms, including anemia, leucopenia, bone lesions (scorbutic-like bone changes and occipital horn), and vesical diverticula. Djoko et al. [112] reviewed $\mathrm{Cu}$ deficiency as a cause of neutropenia, also known as the granulocyte maturation disorder that occurs in the bone marrow and vacuolation in the neutrophils. Cu-deprived diets typically sensitized the animal to infection, prolonged the duration of infection, and increased mortality rates. Selenium (Se) is another essential micronutrient that affects optimal immune responses as it is involved in regulating oxidative stress, redox, and other crucial cellular processes in nearly all tissues and cell types, including those involved in innate and adaptive immune responses. Supplementation with Se may enhance Th1-type immune responses, and certain infectious agents may actually benefit from their antioxidant enzymes. Many of the genes/proteins are involved in iron homeostasis and play a vital role in controlling iron fluxes. It is known that cells of the innate immune system, monocytes, macrophages, microglia and lymphocytes, are able to combat bacterial insults by carefully controlling their iron fluxes. A large amount of iron is required for microbial growth, so bacteria have developed a large variety of iron uptake systems. Inadequate intake of iron could thus lead to suppressed immunity that may predispose the individual to infection by affecting innate, $\mathrm{T}$ cellmediated and adaptive antibody responses. Therefore, low iron intake could be detrimental and cause adverse changes in immune function [113].

Probiotics create a protective barrier in the host against pathogenic bacteria. The intestinal microflora represents about $95 \%$ of the total cell number in the human body and is responsible for the immune response and protection against microbial pathogens. Hundreds of microbial species live in coexistence with humans - on the skin, in the oral cavity, stomach, intestines, urogenital tract, etc. Human health depends on the predominance of beneficial bacteria in this internal microbial biocenosis. These friendly microorganisms, commonly called probiotics, help reduce the amount of "bad" bacteria, which is invaluable to the host organism. Probiotic cultures stimulate the growth of preferred microorganisms, displaces potentially harmful bacteria, and strengthens the body's natural defense mechanisms. In this way, the necessary balance between the intestinal microflora is maintained, which guarantees the intestines' normal function [114]. Disease, antibiotics, and a nutrient-poor diet or a diet lacking in whole foods such as fruits and vegetables can decrease the host's natural microbiota, thereby giving pathogens a route into the system via the gut. Probiotic organisms (Lactobacillus acidophilus, Lactobacillus casei, Enterococcus faecium and Bifidobacterium) are naturally found in fermented foods such as yoghurt, kefir, or kimchi. 
Regular consumption of probiotics is needed to maintain a high population of healthy bacteria in the gut $[12,115]$.

The Role of Nutrition in Immune Function: Poor nutrition is well understood to impair immune function, whether as a result of food shortages or famines in developing countries or malnutrition arising from periods of hospitalization in developed countries. The extent of impairment that results from poor nutrition will depend upon the severity of the deficiency, the presence of infection, and the age of the subject [116]. A single nutrient can also exert multiple diverse immunological effects, as in the case of vitamin $E$, where this vitamin functions as an antioxidant and inhibitor of protein kinase $\mathrm{C}$ activity and may potentially interact with enzymes and transport proteins [117]. For some micronutrients, excessive intake can also be associated with impaired immune responses. For example, supplementation with iron can increase the morbidity and mortality of those in malaria-endemic regions. Proper nutrition has the potential to effectively treat immune deficiencies related to poor intake. There is also a great deal of research interest in whether specific nutritional interventions can further enhance immune function in sub-clinical situations, and thus prevent the onset of infections or chronic inflammatory diseases [116].

\section{Dietary Bioactive Compounds and their Health} Implications: Biologically active (bioactive) compounds are extra-nutritional constituents found in small quantities in foods and, through participation in biochemical mechanisms and physiological processes, have a positive health effect on the body [117]. For example, the consumption of products containing flavonoids has correlated with a significant decrease in body mass index, waist circumference, and total and low-density lipoprotein (LDL) cholesterol in overweight individuals [28]. Flavonoids have also been associated with a decreased risk (at least $-10 \%$ ) of Type 2 diabetes and cardiovascular diseases [118]. Carotenoids have been credited with protecting against ocular disease, cancer, and cardiovascular diseases (CDV) [119]. Studies on the effects of probiotics either in foods or as supplements related to a significantly reduced body weight, BMI, and fat percentage [120] and significant reduction of blood glucose, insulin, and insulin resistance [121]. Fish oils rich in omega-3 fatty acids are associated with healthier fetal development, enhanced cardiovascular function, and reduced Alzheimer's disease [122]. Recently, solid scientific evidence has demonstrated the role of bioactive compounds in supporting the human immune system.

Bioactive Compounds of Plant Origin: Plant sources possess a large number of bioactive compounds and the antioxidant properties that are present in them have a vital role in human's diet. Polyphenols have antioxidant properties, present protection against chronic diseases ([123], and have also demonstrated potential antibacterial, antifungal, and antiviral activities [124-126]. Herbs and spices are used for their taste, antiviral, antimicrobial, antioxidant, and immunity-boosting properties. Popular used herbs and spices such as cinnamon, black pepper, basil, and turmeric play a vital role against SARS-CoV-2 (COVID19) as well as other viral infections [127]. Fruits and vegetables contain significant amounts of vitamins, minerals, antioxidant and other compounds that can reduce inflammation and boost immune function by 
increasing the number of disease-fighting cells in the body.

Flavonoids possess a variety of antiinflammatory properties, some of which are suggested to affect the function of the immune system [128]. These polyphenolic biomolecules widely found in plants have been studied against a large variety of DNA and RNA viruses and may have an impact on the viruses through different mechanisms. For example, flavonoids prevent the attachment and entry of viruses into cells, interfere with the stages of viral replication processes, or translate polyprotein processing that prevents the release of the viruses to infect other cells. Based on antiviral mechanisms of action, flavonoids can be prophylactic inhibitors, therapeutic inhibitors, or indirect inhibitors by interaction with the immune system [129].

Catechins are flavonols that are present in green tea, Camellia sinensis. The epigallocatechin gallate (EGCG) is a catechin that has been extensively studied for its antiviral activity against the following viruses: hepatitis C, hepatitis B, chikungunya virus, herpes simplex virus type 1 , influenza $A$, adenovirus, reovirus vaccinia virus, vesicular stomatitis virus, and, more recently, for the Zika virus [130-135]. Although the mechanisms of these effects of EGCG are not fully understood, EGCG appears to interfere with viral membrane proteins, thereby inhibiting the early stage of infection due to attachment, entry, and membrane fusion [136].

Polyphenols extracts from different parts of pistachios, Pistacia vera, have been screened against herpes simplex virus (HSV), and kernel and seed extracts showed significant antiviral activity. The pistachios polyphenols have been found to interfere with the viral particles directly through inhibition of virus attachment.

The clove (Syzygium aromaticum) compound, eugenol, has been recognized for its antiviral efficacy towards various herpes virus strains and the hepatitis $C$ virus by its action on the synthesis of viral DNA by inhibiting the viral DNA polymerase enzyme [137]. Additional research revealed the antiviral efficacy of $S$. aromaticum aqueous extracts against the herpes simplex virus type 1 (HSV-1) and influenza A virus when combined with acyclovir [138-139].

Mussara-Pizzo et al. [140] tested the antiviral effect of a mix of polyphenols present in natural almond (Prunus dulcis L.) skin, and the skin almond polyphenols presented an antiviral effect against the herpes simplex virus type 2 (HSV-2) and herpes simplex virus type 1 (HSV-1).

Rosemary (Rosmarinus officinalis) has been commonly used as phytomedicine for therapeutic purposes, as a condiment in cooking, as a natural food preservative in the food industry, and as an ornamental garden herb [141]. The main active constituents of rosemary are the following: rosmarinic acid, ursolic acid, carnosic acid, caffeic acid, carnesol, luteolin, camphor, chlorogenic acid, monomeric acid, oleanolic acid, $\alpha$-pinene, camphor, eucalyptol, rosmadial, rosmanol, rosmaquinones $A$ and $B$, secohinokio, and eugenol [142-143].

$R$. officinalis L. has been used globally as a folk medicine for multiple purposes such as immune functionality. There are some animal and in vitro studies available that showed that rosemary solvent extracts might stimulate immune function when used in the form of a topical application, oral administration, or an injection. However, evidence- 
based results for this herb involving the immune system are still lacking.

Marchioni et al. [144] reported the bioactive properties of edible flowers of the Lamiaceae family (Ocimeae and Mentheae tribes): Monarda didyma 'Fireball', Nepeta $\times$ faassenii 'Six Hills Giant', Ocimum basilicum 'Blue Spice’, $O$. basilicum 'Cinnamon', Ocimum $\times$ citriodorum, Salvia discolour, and Salvia microphylla 'Hot Lips'. The biological activity of Valeriana officinalis, the Himalayan Valeriana jatamansi, and Nardostachys jatamansi, belonging to the Caprifoliaceae family are related to their chemical compositions, since sesquiterpenes and monoterpenes significantly contributed to the inhibitory activity and a reconstituted murine neuronal network, but the presence of oxygenated compounds such as aldehydes and ketones is a discriminating factor in determining the order of potency [145]. Artemisia absinthium L. was traditionally used for wound healing. Chlorogenic acid was identified as the most abundant compound. Moreover, $A$. absinthium extract showed antibacterial activity against Gram-negative and Gram-positive foodborne microorganisms [146]). Calluna vulgaris (L.) Hull. was reported for diverse chemical composition and a broad range of biological activity due to the high total amount of phenolic compounds, tannins, flavonoids, hydroxycinnamic acids, proanthocyanidins, and antioxidant activity. Leaf and stem extracts performed antibacterial action against both gramnegative and gram-positive bacteria [147].

Bioactive Compounds of Fungal Origin: Fungi are reported to produce several metabolites with bioactivity against non-transmissible chronic diseases as well as pigments, dyes, antioxidants, polysaccharides, and enzymes that can be explored as substitutes for synthetic food additives. Filamentous fungi are important for the production of many enzymes and organic compounds having a commercial application. Many fungal species are commercially available as supplements or nutraceuticals. Examples of fungal species used as functional foods include many species of microscopic filamentous fungi such as some wellknown Penicillium, Aspergillus, and Fusarium species [148].

Plant endophytes are microorganisms that colonize the interior of plants without causing any immediate negative effects or damages. In some cases, their presence is beneficial due to the ability to synthesize bioactive secondary metabolites, which mimic the natural compounds such as alcohols, esters, ketones that may possess antimicrobial activities against some pathogenic microorganisms. Fungal endophytes such as Aureobasidium pullulans, Paracamarosporium leucadendri, Cladosporium sp., Colletotrichum boninense, $\quad$ Fusarium sp., Hyalodendriella sp., and Talaromyces sp., and Penicillium chrysogenum showed great activity against Gramnegative and Gram-positive bacteria and novel results for two mycobacteria species Mycobacterium bovis and Mycobacterium smegmatis [149].

The secondary metabolites responsible for the pharmacological properties of Schinus terebinthifolius Raddi could be produced by endophytic fungi. The endophytic fungal extracts (Mucor racemosus, Hymenopleella hippophaeicol, Bartalinia pondoensis, Xylaria cf. heliscus, Diaporthe sp., Diaporthe endophytica, Diaporthe eres, Penicillium cinnamopurpureum, Penicillium olsonii, Talaromyces sp., Talaromyces verruculosum, 
Talaromyces atroroseus, Talaromyces minioluteus, Ochrocladosporium elatum, Dothideomycetes sp.) isolated from S. terebinthifolius exhibited antioxidant activity, bactericidal and bacteriostatic activities against Gram-positive and Gram-negative bacterial ATCC strains and methicillin-resistant nosocomial bacteria, and showed hydroxybenzoic acids and 1dodecanol as predominant compounds [150]. The genus Phaeosphaeria (family: Phaeosphaeriaceae, order: Pleosporales) has produced divergent chemical structures, including pyrazine alkaloids, isocoumarins, perylenequinones, anthraquinones, diterpenes, and cyclic peptides, which display a wide scope of biological potentialities [151]. Bioactive compounds obtained by Diaporthe helianthi strain showed antimicrobial reaction and e antagonistic effects on the human pathogenic bacteria Enterococcus hirae, Escherichia coli, Micrococcus luteus, Salmonella typhi, Staphylococcus aureus, phytopathogenic Xanthomonas asc. phaseoli and phytopathogenic fungi [152].

The consumption of fungi as food mainly involves the consumption of mushrooms. Culinary and medicinal mushrooms are well-known as functional foods for their bioactive compounds that have a valuable impact on human well-being. Mushrooms are promising ingredients in the drug and nutraceutical industries, showing antimicrobial, antiviral, antitumor, anti-inflammatory, immunomodulatory, hypoglycaemic, and hepatoprotective properties. Mushrooms (fruiting bodies, mycelia, or their submerged fermentation broth) as wild, edible, or cultivated species are rich in several bioactive compounds [153]. These bioactive metabolites include phenolic compounds, terpenoids, polysaccharides, lectins, steroids, glycoproteins, and several lipid components [154].
Mushroom polysaccharides ( $\alpha$-and $\beta$-glucans, hemicellulose, chitin, xylans, galactans, and mannans) present exciting immunomodulatory, antitumor, antiviral, wound healing, and antiobesity activities [155].

Several studies regarding mushroom antiviral activities showed the beneficial effects of different compounds found in mushrooms. Fungal polysaccharides have been used as a potential source in cancer therapy. Li et al. [156] isolated a glycoprotein (lectin) from Hericium erinaceus, also called the monkey head mushroom, and reported the reverse transcriptase HIV-1 inhibiting the activity of the virus. Zhang et al. [157] lowered the activity of human immunodeficiency virus-1 (HIV-1) reverse transcriptase using laccase isolated from Clitocybe maxima. A protein extracted from Grifola frondosa [158] inhibited the replication of the herpes simplex virus (HSV). Ganomycins extracted from Ganoderma pfeifferi inhibited influenza virus activity [159]. The chemical and bioactive properties of strains of whild Ganoderma sp. from Ghana revealed important nutrient and bioactive molecules such as reducing sugars, organic acids, phenolic compounds, unsaturated and saturated fatty acids, tocopherols, ergosterol, vitamin D and $\beta$-glucans. The chemical and bioactive properties of the species proved to be highly dependent on the strains of the samples (biotic factors) than on the collection site (abiotic factors) [160]. Ganoderma lucidum is abundant in numerous bioactive polysaccharides and some other molecules [161]. The edible mushroom, Dictyophora indusiata, as a source of polysaccharides with main components as $\beta-(\rightarrow 3)-D-$ glucan with side branches of $\beta$ - $(1 \rightarrow 6)$-glucosyl units have been used for the treatment of cancer and immunotherapy, and inflammatory. Trametes 
versicolor (higher fungi or mushroom) has been shown to induce direct cell growth inhibitory effect and apoptosis in cancer cells. $T$. versicolor polysaccharides demonstrated anti-cancer effects via immunostimulant action due to their ability to increase the production of cytokines such as IL-12, which is Th1 related. The immunomodulatory effect of $T$. versicolor polysaccharides in cancer is extended in defenses against bacteria, including against intracellular parasites [162].

Lentinan is a specific class of $\beta$-glucans extracted from the fruit body of the shiitake mushroom (Lentinus edodes). There has been an increasing interest in the use of lentinan for treating disease in both animals and humans [163-164]. The extract from the shiitake mushroom was shown to be efficient as a biological response modifier and immunostimulant in treating hepatitis and HIV [165-166].

Bioactive compounds of milk: Human milk and bovine milk both contain several bioactive proteins that are involved in immune function, defense against infections and development of the infant [167]. Some bioactive proteins such as natural or chemically modified casein, lactoferrin, $\alpha$-lactalbumin, and $\beta$ lactoglobulin present in human and bovine milk have shown productive antiviral activity [168-169]). The functional properties of these types of peptides are revealed only after the degradation of the native protein structure. This degradation may be a consequence of enzymatic hydrolysis, fermentation of milk, and other processes used in dairy production [170]).

Bioactive peptides possess immunomodulatory, antibacterial, antiviral, and antifungal properties and have been extensively explored as antibiotic substitutes in bacterial infections. In more recent times, the use of these peptides has been expanded to include antiviral therapeutics uses (Ahmed et al. 2019) [171]. The hydrophobicity property of peptides is essential for targeting enveloped viruses [172-173].

The peptides released during the digestion of $\alpha$ lactalbumin are formed in the stomach and duodenum and may exert functions during their passage through the jejunum and ileum as well as in the colon. Such peptides present a prebiotic action that stimulates beneficial bacteria and enhances antimicrobial activity, thereby inhibiting the growth of pathogens. Such outcomes may result in a microbiome [174], which in itself may positively affect immune function.

Lactoferrin is an iron-binding glycoprotein that presents higher concentrations in human milk compared to cow's milk and infant formulas. Lactoferrin has antimicrobial properties against bacteria, fungi, and several viruses [175] due to its ability to bind iron [176]. The lactoferrin blocks the viral binding to its target site and thus prevents the virus's spread to host cells [177].

Several mammalian lactoferrins were described to help to prevent viral infection (hepatitis C, inhibited respiratory syncytial virus, hepatitis B virus, adenovirus, poliovirus, hantavirus, sindbis virus, semliki forest virus, echovirus, and enterovirus) [178]. In addition, studies have shown that bovine lactoferrin presented antiviral activity against three Aedes mosquito-transmitted viruses: Dengue, Chikungunya, and Zika virus [156,179].

The milk fat globule membrane (MFGM) is a complex structure containing many cellular components including cholesterol, glycerophospholipids, sphingolipids, and proteins. Among well-described proteins in MFGM, mucin 1 (MUC1) is presented in higher concentrations and has 
shown inhibitory activities against various microorganisms. MUC1 has also been shown to prohibit the transmission of HIV from dendritic cells to T cells and thus may inhibit the transmission of HIV from the mother to the infant via breast-feeding [180]. MUC1 may block the interaction of pathogens with dendritic cells thus contributing to shaping infant immunity [181] and has also been shown to inhibit the hemagglutination of Vibrio cholera and E. coli [167]. Moreover, MUC1 purified from MFGM was indicated to decrease the adherence of Yersinia enterolytica to intestinal membranes. The MFGM fraction has also been found to inhibit rotavirus in vitro [167]. A whey protein concentrate enriched with MFGM may help to protect against diarrhea of both bacterial and viral origin [182].

The efficacy of native and modified whey protein fractions has been tested against the influenza virus subtype H5N1. Whey protein fractions might be useful for the prophylaxis and treatment of influenza viruses and at the same time be a potential low-cost alternative candidate for an anti-influenza agent [183].

Bioactive Lipids: During the past few decades, several bioactive lipids have been identified in nature, and their biological activity has been assessed. Marine omega-3 polyunsaturated fatty acid (PUFA) is an efficacious bioactive lipid that has been widely introduced into food products. PUFAs, especially a group of compounds omega- 6 (n-6) and omega-3 (n3) PUFAs, whose precursors are linoleic acid (18:2 n6) and alpha-linolenic acid (ALA) (18:3n-3), have beneficial effects on human health, particularly on the immune and inflammatory responses [184-185]. Through the action of aerobic desaturation and elongation reactions, these fatty acids are converted to arachidonic acid (20:4 n-6; AA), eicosapentaenoic acid (20:5; n-3 EPA), and docosahexaenoic acid (22:6 n-3; DHA). Low level consumption of PUFAs and subsequent conversion of ALA to DHA and EPA requires supplementation through diets in human. Fatty acid desaturation requires a group of enzymes family that function in double bonds insertion at specified positions of fatty acyl chains. They require molecular oxygen and two electrons to accomplish their desaturation role. They are very crucial to all living organisms, playing a key role in unsaturated fatty acids synthesis [186].

For decades, the effects of dietary PUFAs on the immune system have been investigated, with particular attention on the omega-3 PUFAs-linolenic acid, eicosapentaenoic acid, and docosahexaenoic acid [187].

Some specific immune functions of omega-3 fatty acids were observed in in vitro studies in specific immune cell types, such as phagocytosis by macrophages and neutrophils or Treg differentiation, indicating that these fatty acids are non-specific immune-repressors. Despite the remarkable progress in our understanding of the effects of omega-3 fatty acids on the cells of the immune system, the precise immunoregulatory mechanisms are not fully comprehended.

It is important to mention that in addition to the specific mechanisms of action of omega-3 fatty acid regulation of immune cell function, omega-3 fatty acids are incorporated into the cellular membrane via in vitro stimulation or via dietary supplementation [188-190]. Moreover, the multiple double bonds of PUFAs cause a bend in the carbon chain, and PUFAs cannot stack as closely within cellular membranes as saturated fatty acids can. Consequently, the 
incorporation of polyunsaturated fatty acids increases the fluidity of cellular membranes [191].

Another unsaturated fatty acid, AA, showed effects against gram-positive and gram-negative bacteria, fungi, and enveloped viruses, including influenza and HIV. The mechanism of action of AA and other fatty acids may include their ability to induce leakage and even lysis of microbial cell membranes (including disruption of viral protein envelopes). In addition, fatty acids may confer various cellular metabolic effects, including, but not limited to, inhibition of respiratory activity and affecting the transportation of amino acids.

Recently, Das [192] discussed the role of AA and other unsaturated fatty acids in the inactivation of enveloped viruses including SARS-CoV-2, SARS, and MERS. It was reported that AA, EPA, and DHA and their anti-inflammatory metabolites such as lipoxin A4, resolvins, protectins, and maresins were essential for the limitation and resolution of inflammation and that they function as endogenous antimicrobial molecules.

Bioactive lipids are beneficial due to their ability to inactivate enveloped viruses and several other harmful microbes, enhance macrophage phagocytic capacity, augment wound healing and tissue regeneration, promote hematopoiesis and protect normal cells from both endogenous and exogenous cytotoxic agents with relatively few adverse effects [193].

Food Ingredients and Active Compounds against COVID-19 Disease: The oral supplementation or intravenous administration of food bioactive and nutraceuticals has been proposed as an alternative approach against COVID-19 disease based mainly on their anti-inflammatory properties, for example, some supplementations of food bioactive compounds can inhibit virus (e.g., SARS, MERS, and COVID-19) activity by disrupting protein envelopes $[9,11]$ using smart harvesting techniques. For instance, such compounds can enhance the response of type 1 interferon to RNA viruses such as influenza and coronavirus [149]. Plant secondary metabolites (e.g., ß-carboline, quinoline alkaloids such as cinchonine, skimmianin, dictamine, and quinine, as well as isoquinoline alkaloids such as emetine, berberine, and sanguinarine) can act as DNA intercalators (similar to chloroquine that has been unsuccessful in positively affecting clinical outcomes in the treatment of COVID-19) inhibiting the replication of the virus [194]. Another anti-replication mechanism is through the strong binding affinity of SARS-CoV-2 spike protein to human ACE-2 (angiotensin-converting enzyme 2). This enzyme is a type I transmembrane metallocarboxypeptidase that is expressed primarily in the renal tubular epithelium and in vascular endothelial cells, but also in the lungs and kidney [195-197]. Various studies have referred to ACE-2 as an entry receptor for SARS-CoV-2 in the body [198199]. In particular, the spike proteins on the virus surface bind onto ACE-2 and diffuse the virus into the target cells [200]. Subsequently, compounds that exhibit a binding affinity for the core amino acid of ACE-2 have been proposed as potential preventive or therapeutic agents (these compounds mainly attack free viral particles and, to a lesser extent, viruses that have already entered host cells) since they can interfere with or avoid the host-viral interaction $[194,201]$. Bioactive lipids inhibit ACE, which is a precursor of ACE-2 and thus suppress ACE2expression, reducing the availability of receptors to SARS-CoV-2 and subsequently restricting the virus's ability to enter the target cell [202]. 
Using simulations of binding free energy and molecular dynamics, stilbene-based compounds such as resveratrol are potential anti-COVID-19 candidates that can theoretically disrupt the virus's spike protein [203]. Relevant action mechanisms have also been proposed for other bioactive compounds such as folic acid [11]. Folic acid is a water-soluble vitamin and can inhibit the furin activity that facilitates the separation between ACE-2 and spike proteins of SARS-CoV-2s [204]. Adem et al. [205] conducted a molecular docking study to identify the ability of 80 flavonoid compounds to bind 3-chymotrypsin-like protease (3CLpro), which is known to be an important enzyme for the replication of SARS-CoV. Other polyphenols and flavonoids such as those in the following list: protocatechuic acid, punicalagin, theaflavin gallate, kaempferol, theaflavin digallate [206], pedunculagin, tercatain, punicalin, [207], epigallocatechin gallate [208], riboflavin, daidzein, genistein, phycocyanobilin, cyanidin [209], hispidin, lepidine E [210], and hesperidin [211] have been proposed as potential inhibitors of the main COVID-19 protease in similar studies.

Hesperidin and other flavonoids have been stated to possess a better binding attitude against COVID-19 than common drugs such as nelfinavir, chloroquine, and hydroxychloroquine sulfate [205, 212]. With regard to different flavonoids, a thorough bioinformatic analysis of small molecules interacting with ACE-2 using the supercomputer-based ensemble docking and indicated the structural analogue eriodictyol (5,7,30,40-tetrahydroxyflavanone) of luteolin as the most potent inhibitor of SARS-CoV-2 [213]. Finally, quercetin and flavonoids from different plants (e.g., litchi seeds) have shown similar activity when applied in traditional Chinese medicine [214]. In general, supplementation with dietary flavonoids up to $1-2 \mathrm{~g} /$ day is considered to be safe, but higher cumulative dosages should be avoided as they can negatively affect the metabolism of the liver [215216].

Although these theoretical approaches and hypotheses about the potential role of plant secondary metabolites against COVID-19 seem to be reasonable, most have not been justified yet either with in vitro studies or with clinical trials. In one of the first relevant studies, Murphy et al. [217] used an in vitro lung injury model to study the activity of $\beta$ glucans from the shiitake mushroom. The authors reported that $\beta$-glucans reduced the inflammatory responses associated with acute respiratory distress syndrome (ARDS) in vitro. Those results included reduced cytokine production, oxidative stress, necrosis and apoptosis, suggesting the potential for the amelioration of COVID-19 by helping to prevent the cytokine storm. The cytokine storm occurs when white blood cells accumulate as a result of infections such as COVID-19, thereby releasing inflammatory cytokines. It is a condition in which the immune system gets out of control and damages the body. The concentration of pro-inflammatory cytokines leads to severe systemic inflammation with damage to many organs and systems and can lead to multiorgan failure. The causes of a cytokine storm are infections, autoimmune diseases and some types of immunotherapy.

The differential in vitro immunomodulatory and pulmonary cytoprotective effects thus has been attributed in part to variance in the b-glucan structure that has relevance to COVID-19 interventions. ARDS was evident in severe complications experienced by intensive care unit COVID-19 patients in China [218], where the specific involvement in reducing cytokines 
IL-1b and IL-6 production was a strategy for COVID-19 intervention [219].

Novel therapies are urgently required to address ARDS that is associated with severe respiratory failure that results in an approximately $40 \%$ mortality rate. The up-regulation of pro-inflammatory cytokines associated with lung parenchyma injury is an important causation element of ARDS [220-221]. Beta-Glucans from shiitake mushrooms also reduced populations of a multiple-antibiotic resistant isolate, Klebsiella pneumoniae, in an in vivolung infection model [222]. The findings showed that bglucans improved lung physiological parameters, reduced white cell count protein inflammation in the lungs, reduced bacterial levels in the bronchoalveolar lavage and arterial blood parameter, and supported vital partial pressure of oxygen ( $\mathrm{pO} 2$ ) along with promoting lung cellular repair. The same research group recently reported on a novel means of delivering nebulized bioactive in aerosols for effective lung delivery and which has potential implications for use in smart nutraceuticals in the future treatment and recovery of COVID-19 patients [223].

The aforementioned study also supports the findings of Bedirli et al. [224] from an experimental sepsis model in which a b-glucan attenuated inflammatory cytokine release (tumour necrosis factor-a, IL-1b and IL-b) prevented acute lung injury. While there has been an emergence of smart infection models, such as those for lung $[217,222]$ or gut delivery [163], there is a pressing need to pursue controlled clinical studies on the use of b-glucans to prove its efficacy for human health. Luo et al. [225] investigated the anti-inflammatory effects of bilberry (Vaccinium myrtillus L.) extract (containing 42.04\% anthocyanin) on alleviating liver injury and croton (flowering plant genus from Euphorbiaceae family) oil-induced ear edema using a rodent infection model.

The bilberry extract effectively inhibited liver inflammation and croton oil-induced ear edema caused by $P$. acnes. Specifically, the bilberry extract suppressed the protein levels of nuclear factor-kB, tumour necrosis factor-a, and inducible nitric oxide synthase, and increased liver mRNA levels of IL-6, TNF- $\alpha$, IL-6 -1b, and inducible nitric oxide synthase. The bilberry extract treatment also reduced liver malondialdehyde and nitric oxide contents. These results suggest the anti-inflammatory potential for future use of bilberry extract against COVID-19 in foods with functional properties, rabbiteye blueberry (Vaccinium ashei Reade) anthocyanin extracts were also recently reported for their capacity and underlying mechanisms in protecting against lipopolysaccharide (LPS)-stimulated inflammation in vitro [226]. Enzyme-linked immunosorbent assay (ELISA) studies indicated that blueberry extract restricted the production of IL-6 IL-6-1 $\beta$, prostaglandin E2, interferon- $\gamma$ and nitric oxide. Further analysis with real-time PCR showed that in LPS-stimulated RAW 264.7 cells, the mRNA expression levels of cyclooxygenase 2, tumour necrosis factor- $\alpha$, monocyte chemoattractant protein-1, IL-6, and IL-6-1ß were suppressed. However, detailed mechanistic information underpinning the use of anthocyanin in disease mitigation remains to be elucidated.

The medicinal plants are investigated for their antiviral sections. The aqueous-ethanolic extract from Pelargonium sidoides roots has been shown to shorten viral infections as it was widely used in the treatment of acute airway infections. $P$. sidoides radix extract was reported for its antiviral characteristics due to the expression of virus binding cell membrane 
and host defense supporting proteins on primary human bronchial epithelial cells [227]. Other reviews and studies have covered the role of vitamins (particularly A, E, and D) against COVID-19 transmission. Isotrenion, which is a derivative of vitamin $A$, was recently suggested to restrict the activity of angiotensin-converting enzyme 2 (ACE2) [228]. In contrast, it is known that the decrease in levels of vitamins D and E in cattle could increase the infection probabilities for bovine coronavirus [229].

The increased risk of acute respiratory distress and lung injury syndrome with COVID-19 infection is attributed to vitamin D deficiency. Numerous studies with well- established data [230] have shown that vitamin $D$ possesses immunomodulatory and antiinflammatory properties as well as antiviral effects that may enhance the immune system [231]. Ilie, Stefanescu and Smith [232] confirmed this using randomized population studies, whereas Daneshkhah et al. [233] combined data from two clinical studies to suggest that vitamin D may reduce COVID-19 severity by suppressing the cytokine storm in patients. Lau et al. [234] conducted a retrospective observational study, reviewing the medical records of COVID-19 and suggesting that vitamin $D$ insufficiency may play a role in the progress of COVID-19 disease. However, to validate these kinds of hypotheses, more randomized controlled studies are needed since the latest investigation did not adequately address risk-stratify subjects.

Another potential prevention strategy to be used against the transmission of SARS-CoV-2 may be the consumption of fruits, vegetables and herbs. Herbal medicines (e.g. traditional Chinese or Unani) are rich in dietary antioxidants such as polyphenols and vitamins [235] and have shown some promising results in the treatment of relevant diseases. For example, Astragulus membranaceus extracts have shown in vitro anti-influenza virus activity [236]. Moreover, the consumption of ginseng root has been proposed for the prevention of influenza [237]. Hui et al. [238] revised the outcomes of a population, cohort, and clinical studies that used Chinese herbal formulas for the prevention of SARS and H1N1 influenza transmission in older people and high-risk populations, suggesting the potential protective role of such formulas against COVID-19 disease. The most frequently used herbs in these studies included Fructus forsythia (Lianqiao), Radix glycyrrhizae (Gancao), Radix saposhnikoviae (Fangfeng), Radix astragali (Huangqi), Lonicerae Japonicae Flos (Jinyinhua), and Rhizoma Atractylodis Macrocephalae (Baizhu) [238]. Luo et al. [239] conducted an empirical study based on the treatment of 54 COVID-19 patients from Wuhan (China), noting that traditional Chinese medicine improved patient recovery time. Ang et al. [240] analyzed 28 (26 Chinese and 2 Korean government-issued) guidelines and numerous herbal formulas, identifying different patterns for mild, moderate, severe, and recovery stages of COVID-19 disease. Glycyrrhizae Radix et Rhizoma was the most recommended herb in the Chinese guidelines. Nevertheless, the potential protective role of the above formulas must still be confirmed with prospective and rigorous clinical studies [238, 240]. Nutrition has a strong influence on immune status, so the role of food in immune function has been extensively studied in the dedicated issue of Nutrition. The importance of macro- and micronutrients is determined by the ability of the nutrients to create a balance for the physicochemical functions in the human body. Thus, during respiratory tract infections, some groups of foods are more important for consumption than others. Many foods, 
particularly fruit and vegetables, have some level of antioxidant activity, which makes them important source of bioactive compounds and antioxidants. Some dietary components have both anti-oxidative and anti-inflammatory properties. Dietary fatty acids, and particularly the omega- 6 to omega- 3 ratio, may influence the immune response in different situations with omega-3 polyunsaturated fatty acids (PUFAs) generally exhibiting a protective effect. Oily fish and some vegetable oils are the best dietary sources of omega-3 PUFAs. In addition, milk, eggs, fish, meat, and plants with milk and dairy proteins have significant inhibitory activity due to the peptides possessing angiotensin converting enzyme inhibitory activity. A number of studies have shown that fermented foods and probiotic supplements increases angiotensin converting enzyme inhibitory properties and are thus used in the treatment of respiratory tract infections, and in the prevention and treatment of COVID-19 [108].

\section{CONCLUSION}

Viral infectious diseases such as SARS-CoV-2 (COVID19) pose a major threat to human health and result in a significant breakdown of the human body's immunity against pathogenic infections. The human body requires a strong immune system that is robust to help ward off possible viral attacks and to help prevent the proliferation of infections in the event of pathogenic or viral exposure. It is thus imperative to consider holistic approaches to boosting the human immune system through nutrition, physical exercise, and a broader perspective on the benefits of bioactive food compounds and food ingredients. Such a paradigm shift with regard to nutraceuticals has been thoroughly elucidated in this review as an alternative to the use of drugs for immune support. Generally, for immune support, a focus on nutraceuticals that do not have any health side effects are recommended, as opposed to drugs that are associated with long-term side effects. Thus, the global (both geographically and physiologically speaking) fight to prevail against COVID-19 requires a concerted effort and a change in lifestyle and nutrition. This means that our overarching aim should be focused on the prevention of viral infections by naturally and proactively boosting our immune cells and defense systems.

Abbreviations: ACE-2: Angiotensin-Converting Enzyme 2, ALA: Alpha-linolenic acid, APCs: Antigenpresenting cells, AA: Arachidonic acid, BCR: B-cell receptor, CSF: Colony-stimulating factors, C3a and C5a: Complement fractions, DAMPS: Damageassociated molecular patterns, DC: Dendritic cells, DHA: Docosahexaenoic acid, DTH: Delayed-Type Hypersensitivity, EGCG: Epigallocatechin Gallate, ER: Estrogen Receptors, ERE: Estrogen Response Elements, HSV: Herpes Simplex virus, HIV-1: Human Immunodeficiency Virus-1, HLA: Human Leukocyte Antigen, HMOs: Human Milk Oligosaccharides, IG: Immunoglobin, IC: Immune Complex, IL-1 $\beta$ : Interleukin-1-beta, Interleukin-1-6, IL-15: Interleukin15, Ils: Interleukins, IFNs: Interferons, JAK-STAT: Janus Kinase/ Signal Transducer and Activator of Transcription, LDL: Low-Density Lipoprotein, MHC: Major Histocompatibility Complex, MERS: Middle East Respiratory Syndrome, MAPK: MitogenActivated Protein Kinase, MFGM: Milk Fat Globule Membrane, MUC1: Mucin 1, NKC: Natural Killer cell, NLRs: NOD-like Receptors, NOD: Nucleotide Oligomerization Domains, NF-kB: Nuclear factor kappa-light-chain-enhancer of activated B cells (NFкB), n-3: Omega-3, n-6: Omega-6, PAMPs: Pathogenassociated molecular patterns, PUFA: 
Polyunsaturated Fatty Acid, RNS: Reactive Nitrogen Species, ROS: Reactive Oxygen Species, SARS: Severe Acute Respiratory Syndrome, TCR: T-cell Receptor, TLRs: Toll-like Receptors, TGFs: Transforming Growth Factor, TNFs: Tumor Necrosis Factors, TNF- $\alpha$ : Tumor Necrosis Factor-alpha, URTI: Upper respiratory tract infections, MiRNAs: X-linked micro-RNAs, 3CLpro: 3chymotrypsin-like protease

Authors' Contributions: All authors contributed equally to the manuscript. Authors SAI, RDA and HF conceptualized and designed the review. Author SAI provided funding support.

\section{REFERENCES}

1. Ibrahim SA, Gyawali R, Fidan H: Self-Defense: A Practical Approach to Combatting COVID-19". Acta Scientific Nutritional Health 2020, 4.7: 33-37.

2. Kumar GD, Mishra A, Dunn L, Townsend A, Oguadinma IC, Bright KR, Gerba CP: Biocides and Novel Antimicrobial Agents for the Mitigation of Coronaviruses. Frontiers in Microbiology 2020, 11: 112. http://dx.doi.org 10.3389/fmicb.2020.01351

3. Prompetchara E, Ketloy C, Palaga T: Immune responses in COVID-19 and potential vaccines: Lessons learned from SARS and MERS epidemic. Asian Pacific Journal of Allergy and Immunology 2020, 38(1): 1-9.

4. Olaimat AN, Aolymat I, Elsahoryi N, Shahbaz HM, Holley RA: Attitudes, Anxiety, and Behavioral Practices Regarding COVID-19 among University Students in Jordan: A Cross-Sectional Study. The American Journal of Tropical Medicine and Hygiene 2020a, 103(3): 11771183.

5. Olaimat AN, Aolymat I, Shahbaz HM, Holley RA: Knowledge and Information Sources About COVID-19 Among University Students in Jordan: A Cross-Sectional Study. Frontiers in Public Health 2020b, 8: 254.

6. Kwok KO, Lai F, Wei WI, Wong SYS, Tang JW: Herd immunity-estimating the level required to halt the
Acknowledgments: This publication was made possible by grants or project numbers NC.X337-5-21170-1 and NC.X341-5-21-170-1 from the National Institute of Food and Agriculture (NIFA). Its contents are solely the responsibility of the authors and do not necessarily represent the official views of NIFA. The authors would also like to acknowledge the financial support of the Department of Family and Consumer Sciences and the Agricultural Research Station at North Carolina Agricultural and Technical State University (Greensboro, NC, 27411 USA).

Conflicts of Interest: The authors declare no conflict of interest.

COVID-19 epidemics in affected countries. Journal of Infection 2020, 80(6), 32-33.

7. Paul WE: Bridging Innate and Adaptive Immunity. Cell 2011, 147, 1212-1215.

8. Chaplin DD: Overview of the immune response. Journal of Allergy and Clinical Immunology 2010, 125(2): 3-23.

9. Galanakis CM: The Food Systems in the Era of the Coronavirus (COVID-19) Pandemic Crisis. Foods 2020, 9: 523.

10. Rowan NJ, Galanakis CM: Unlocking challenges and opportunities presented by COVID-19 pandemic for cross-cutting disruption in agri-food and green deal innovations: Quo Vadis? Science of the Total Environment 2020, 748. doi.10.1016/j.scitotenv.2020.141362

11. Galanakis CM, Aldawoud TMS, Rizou M, Rowan, N, Ibrahim, S: Food Ingredients and Active Compounds against the Coronavirus Disease (COVID-19) Pandemic: a Comprehensive Review. Foods 2020, 9(11): 1701.

12. Calder PC, Kew S: The immune system: a target for functional foods? British Journal of Nutrition 2002: 88(S2), 165-176

13. Chaplin DD: Overview of the human immune response. Journal of Allergy and Clinical Immunology 2006, 117(2): S430-S435. 
14. Cruvinel MW, Mesquita JD, Araújo J, Catelan T, Andrade L: Immune system-part I. Fundamentals of innate immunity with emphasis on molecular and cellular mechanisms of inflammatory response. Revista Brasileira de Reumatologia 2010, 50(4): 434-461.

15. Nelson RJ: Seasonal immune function and sickness responses, Trends in Immunology 2004, 25(4), 187-192.

16. Pennell LM, Galligan CL, Fish EN: Sex Affects Immunity. Journal of Autoimmunity 2012, 38(2-3): 282-91.

17. Abram QH, Dixon B, Katzenback BA: Impacts of Low Temperature on the Teleost Immune System. Biology 2017, 6(4):39. doi:10.3390/biology6040039

18. Weyh C, Krüger K, Strasser B: Physical Activity and Diet Shape the Immune System during Aging. Nutrients, 2020, 2(3): 622. doi:10.3390/nu12030622.

19. Turvey SE, Broide DH: Innate immunity. Journal of Allergy and Clinical Immunology 2010, 125(2): S24-S32.

20. Janeway CA, Medzhitov R: Innate immune recognition. Annual Review of Immunology 2002, 20(1): 197-216.

21. Gonzalez S, González-Rodríguez AP, López-Soto A Huergo-Zapico L, López-Larrea C, Suárez-Álvarez B: Conceptual aspects of self and nonself discrimination. Self/nonself 2011, 2(1): 19-25.

22. The MHC sequencing consortium: Complete sequence and gene map of a human major histocompatibility complex. Nature 1999, 401(6756): 921-923.

23. Janeway CA, Travers P, Walport M, Shlomchik MJ: The major histocompatibility complex and its functions. In Immunobiology: The Immune System in Health and Disease. 5th edition: Garland Science, 2001.

24. Abbas A, Lichtman A: Antigen capture and presentation to lymphocytes. Basic Immunology: Functions and Disorders of the Immune System. 2009, 49-70.

25. Kindt TJ, Goldsby RA, Osborne BA, Kuby J: Kuby immunology: Macmillan. (2007)

26. Kambayashi T, Laufer TM. A typical MHC class IIexpressing antigen-presenting cells: can anything replace a dendritic cell? Nature Reviews Immunology 2014, 14(11): 719-730.

27. Gruen JR, Weissman SM: Evolving views of the majo histocompatibility complex. Blood, The Journal of the American Society of Hematology 1997, 90(11): 42524265.
28. González-Sarrías A, Combet E, Pinto P, Mena P, Dall'Asta M, Garcia-Aloy M, Rodríguez-Mateos A, Gibney ER, Dumont J, Massaro M, Sánchez-Meca J, Morand C, García-Conesa MT: A Systematic Review and MetaAnalysis of the Effects of Flavanol-Containing Tea, Cocoa and Apple Products on Body Composition and Blood Lipids: Exploring the Factors Responsible for Variability in Their Efficacy. Nutrients 2017, 9(7): 746.

29. Janeway CA: The immune system evolved to discriminate infectious nonself from noninfectious self. Immunology Today 1992, 13(1), 11-16.

30. Roach JC, Glusman G, Rowen L, Kaur A, Purcell MK, Smith KD, Hood LE, Aderem A: The evolution of vertebrate Toll-like receptors. Proceedings of the National Academy of Sciences 2005, 102(27), 95779582.

31. Kärre K, Ljunggren HG, Piontek G, Kiessling R: Selective rejection of $\mathrm{H}$-2-deficient lymphoma variants suggests alternative immune defense strategy. Nature 1986, 319(6055), 675-678.

32. Banchereau J, Briere F, Caux C, Davoust J, Lebecque S, Liu Y, Pulendran B, Palucka K: Immunobiology of dendritic cells. Annual Review of Immunology 2000, 18(1): 767-811.

33. Cerwenka A, Lanier LL: Natural killer cells, viruses and cancer. Nature Reviews Immunology 2001, 1(1): 41-49.

34. Ferrero-Miliani L, Nielsen O, Andersen P, Girardin S: Chronic inflammation: importance of NOD2 and NALP3 in interleukin-1 $\beta$ generation. Clinical \& Experimental Immunology 2007, 147(2): 227-235.

35. Medzhitov R: Inflammation, new adventures of an old flame. Cell 2010, 140(6): 771-776.

36. Medzhitov R: Origin and physiological roles of inflammation. Nature 2008, 454(7203): 428-435.

37. Zhou $\mathrm{Y}$, Hong $\mathrm{Y}$, Huang $\mathrm{H}$ : Triptolide attenuates inflammatory response in membranous glomerulonephritis rat via downregulation of NF-KB signaling pathway. Kidney and Blood Pressure Research 2016, 41(6): 901-910.

38. Takeuchi O, Akira S: Pattern recognition receptors and inflammation. Cell 2010, 140(6): 805-820.

39. Matzinger P: The danger model: a renewed sense of self. Science 2002, 296(5566): 301-305 
40. Chen L, Deng H, Cui H, Fang J, Zuo Z, Deng J, Li Y, Wang $\mathrm{X}$, Zhao L: Inflammatory responses and inflammationassociated diseases in organs. Oncotarget 2018, 9(6): 7204.

41. Jabbour H, Sales K, Catalano R, Norman J: Inflammatory pathways in female reproductive health and disease. Reproduction 2009, 138(6): 903.

42. Turner MD, Nedjai B, Hurst T, Pennington DJ: Cytokines and chemokines: at the crossroads of cell signalling and inflammatory disease. Biochimica et Biophysica Acta (BBA)-Molecular Cell Research 2014, 1843(11): 2563 2582.

43. Czaja AJ: Hepatic inflammation and progressive liver fibrosis in chronic liver disease. World journal of gastroenterology: WJG 2014, 20(10): 2515.

44. Liu Z, Wang $Y$, Wang $Y$, Ning $Q$, Zhang $Y$, Gong $C$, Zhao W, Jing G, Wang Q: Dexmedetomidine attenuates inflammatory reaction in the lung tissues of septic mice by activating cholinergic anti-inflammatory pathway. International Immunopharmacology 2016, 35, 210-216.

45. Lawrence $\mathrm{T}$ : The nuclear factor NF-kB pathway in inflammation. Cold Spring Harbor Perspectives in Biology 2009, 1(6). doi.10.1101/cshperspect.a001651.

46. Libby P: Inflammatory mechanisms: the molecular basis of inflammation and disease. Nutrition Reviews, 2007, 65(suppl_3), 140-146.

47. Janeway CA, Travers $P$, Walport $M$, Shlomchik $M$ : Immuno Biology: The Immune system in Health and Disease. In: New York and London: Garland Sciences, Churchill Livingston, 2005.

48. Lange C, Hemmrich G, Klostermeier UC, López-Quintero JA, Miller DJ, Rahn T, Weiss Y, Bosch TC, Rosenstiel P: Defining the origins of the NOD-like receptor system at the base of animal evolution. Molecular Biology and Evolution 2011, 28(5): 1687-1702.

49. Ghosh S, May MJ, Kopp, EB: NF-KB and Rel proteins: evolutionarily conserved mediators of immune responses. Annual Review of Immunology 1998, 16(1): 225-260.

50. Friedman R, Hughes AL: Molecular evolution of the NFKB signaling system. Immunogenetics 2002, 53(10-11): 964-974.
51. Ashley NT, Weil ZM, Nelson RJ: Inflammation: mechanisms, costs, and natural variation. Annual Review of Ecology, Evolution, and Systematics. 2012, $43: 385-406$

52. Nathan C: Points of control in inflammation. Nature 2002, 420(6917): 846-852

53. Serhan $\mathrm{CN}$, Savill J: Resolution of inflammation: the beginning programs the end. Nature Immunology 2005, 6(12): 1191-1197.

54. Müller L, Pawelec G: Aging and immunity-impact of behavioral intervention. Brain, Behavior, and Immunity 2014, 39: 8-22.

55. Gruver A, Hudson L, Sempowski G: (2007). Immunosenescence of ageing. The Journal of Pathology: A Journal of the Pathological Society of Great Britain and Ireland 2007, 211(2): 144-156.

56. Gonzalo S: Epigenetic alterations in aging. Journal of Applied Physiology 2010, 109(2): 586-597.

57. Bauer ME: Stress, glucocorticoids and ageing of the immune system. Stress 2005, 8(1): 69-83.

58. Aguirre-Gamboa R, Joosten I, Urbano PCM, van der Molen RG, van Rijssen $E$, van Cranenbroek B, Oosting $M$, Smeekens S, Jaeger M, Zorro M, Withoff S, van Herwaarden AE, Sweep FCGJ, Netea RT, Swertz MA, Franke L, Xavier RJ, Joosten LAB, Netea MJ, Wijmenga C, Kumar V, Li Y, Koenen HJPM: Differential Effects of Environmental and Genetic Factors on $\mathrm{T}$ and B Cell Immune Traits. Cell Reports 2016, 17: 2474-2487.

59. Suchard M: Immunosenescence: ageing of the immune system. South African Pharmaceutical Journal 2015, 82(8): 28-31.

60. Hattaf K, Yousfi N: Modeling the Adaptive Immunity and Both Modes of Transmission in HIV Infection. $\begin{array}{lll}\text { Computation } & \text { 2018, } & 6(2):\end{array}$ doi:10.3390/computation6020037.

61. Abusarah J, Khodayarian F, Cui Y, El-Kadiry AEH, Rafei M: Thymic rejuvenation: are we there yet. Gerontology 2018, 41-62

62. Fulop T, Larbi A, Dupuis G, Le Page A, Frost EH, Cohen AA, Witkowski JM, Franceschi C: Immunosenescence and Inflamm-Aging As Two Sides of the Same Coin: Friends or Foes? Front Immunology 2017, 8, 1960. https://doi.org/10.3389/fimmu.2017.01960. 
63. Caruso C, Buffa S, Candore G, Colonna-Romano G, Dunn-Walters D, Kipling D, Pawelec G: Mechanisms of immunosenescence. Immunity \& Ageing 2009, 6(1),10. doi:10.1186/1742-4933-6-10.

64. Valiathan R, Ashman M, Asthana D: Effects of Ageing on the Immune System: Infants to Elderly. Scandinavian Journal of Immunology 2016, 83: 255-266.

65. Shaw AC, Joshi S, Greenwood H, Panda A, Lord JM: Aging of the innate immune system. Current opinion in immunology 2010, 22(4), 507-513.

66. Fernández-Morera JL, Calvanese V, Rodríguez-Rodero S, Menéndez-Torre $E$, Fraga $M$ : Epigenetic regulation of the immune system in health and disease. Tissue Antigens 2010, 76(6): 431-439.

67. Bonilla FA, Oettgen HC: Adaptive immunity. Journal of Allergy and Clinical Immunology 2010, 125(2): 33-40.

68. Buffa S, Pellicanò M, Bulati M, Martorana A, Goldeck D, Caruso C, Pawelec G, Colonna-Romano G: A novel B cell population revealed by a CD38/CD24 gating strategy: CD38- CD24- B cells in centenarian offspring and elderly people. Age 2013, 35(5), 2009-2024.

69. Fuentes $\mathrm{E}$, Fuentes $\mathrm{M}$, Alarcon M, Palomo I: Immune system dysfunction in the elderly. Anais da Academia Brasileira de Ciências 2017, 89(1): 285-299.

70. Palmer DB: The effect of age on thymic function. Frontiers in Immunology 2013, 4: 316.

71. Sikora E: Activation-induced and damage-induced cell death in aging human T cells. Mechanisms of Ageing and Development 2015, 151: 85-92.

72. Holdcroft A: Gender bias in research: how does it affect evidence-based medicine? Journal of the Royal. Society of Medicine 2007, 100, 2-3.

73. Oertelt-Prigione $\mathrm{S}$ : The influence of sex and gender on the immune response. Autoimmunity Reviews 2012, 11(6-7): A479-A485.

74. Ghazeeri G, Abdullah L, Abbas O: Immunologica differences in women compared with men: overview and contributing factors. American Journal of Reproductive Immunology 2011, 66(3): 163-169.

75. Hewagama A, Patel D, Yarlagadda S, Strickland FM, Richardson BC: Stronger inflammatory/cytotoxic T-cell response in women identified by microarray analysis. Genes and Immunity 2009, 10(5): 509-516.
76. Voskuhl R: Sex differences in autoimmune diseases. Biology of sex differences 2011, 2(1): 1. doi: 10.1186/2042-6410-2-1

77. Klein SL, Dhakal S, Ursin RL, Deshpande S, Sandberg K, Mauvais-Jarvis F: Biological sex impacts COVID-19 outcomes. PLoS Pathogens 2020, 16(6). https://doi.org/10.1371/journal.ppat.1008570

78. Scully EP, Haverfield J, Ursin RL, Tannenbaum C, Klein SL: Considering how biological sex impacts immune responses and COVID-19 outcomes. Nature Reviews Immunology 2020, 20: 442-447.

https://doi.org/10.1038/s41577-020-0348-8.

79. Meng Y, Wu P, Lu W, Liu K, Ma K, Huang L, Cai J, Zhang H, Qin Y, Sun H, Ding W, Gui L, Wu P: Sex-specific clinical characteristics and prognosis of coronavirus disease-19 infection in Wuhan, China: A retrospective study of 168 severe patients. PLoS Pathog 2020, 16(4). https://doi.org/10.1371/journal.ppat.1008520

80. Ruggieri A, Anticoli S, D'Ambrosio A, Giordani L, Viora M: The influence of sex and gender on immunity, infection and vaccination. Annali dell'Istituto Superiore di Sanita 2016, 52(2): 198-204.

81. Ortona E, Pierdominici M, Rider V: Editorial: Sex Hormones and Gender Differences in Immune Responses. Front Immunology 2019, 10: 1076. https://doi.org/10.3389/fimmu.2019.01076

82. Klein SL: Immune cells have sex and so should journal articles. Endocrinology, 2012, 153(6): 2544-2550.

83. Tam A, Morrish D, Wadsworth S, Dorscheid D, Man SP, Sin DD: The role of female hormones on lung function in chronic lung diseases. BMC Women's Health 2011, 11(1). doi: 10.1186/1472-6874-11-24

84. Zeng F, Dai C, Cai P, Wang J, Xu L, Li J, Hu G, Wang Z, Zheng F, Wang L: A comparison study of SARS-CoV-2 IgG antibody between male and female COVID-19 patients: A possible reason underlying different outcome between sex. Journal of Medical Virology 2020, 92(10): 2050-2054. https://doi.org/10.1002/jmv.25989

85. Nyenhuis SM, Krishnan JA, Berry A, Calhoun WJ, Chinchilli VM, Engle L, Grossman N, Holguin F, Israel E, Kittles RA, Kraft M, Lazarus SC, Lehman EB, Mauger DT, Moy JN, Peters SP, Phipatanakul W, Smith LJ, Sumino K, Szefler SJ, Wechsler ME, Wenzel S, White SR, Ackerman SJ: Race is associated with differences in airway 
inflammation in patients with asthma. Journal of Allergy and Clinical Immunology, 2017, 140(1): 257-265. doi: 10.1016/j.jaci.2016.10.024.

86. Grimaldi CM, Jeganathan V, Diamond B: Hormonal regulation of $B$ cell development: $17 \beta$-estradiol impairs negative selection of high-affinity DNA-reactive B cells at more than one developmental checkpoint. The Journal of Immunology 2006, 176(5): 2703-2710.

87. Klein SL. Hormonal and immunological mechanisms mediating sex differences in parasite infection. Parasite Immunology 2004, 26(6-7), 247-264.

88. Gleicher N, Barad DH: Gender as risk factor for autoimmune diseases. Journal of Autoimmunity 2007 28(1): 1-6.

89. Fish EN: The X-files in immunity: sex-based differences predispose immune responses. Nature Reviews Immunology 2008, 8(9): 737-744.

90. Pinheiro I, Dejager L, Libert C: X-chromosome-located microRNAs in immunity: might they explain male/female differences? The $\mathrm{X}$ chromosome-genomic context may affect X-located miRNAs and downstream signaling, thereby contributing to the enhanced immune response of females. Bioessays 2011, 33(11): 791-802.

91. De Souza Melo A, da Penha Sobral AIG, Marinho MLM, Duarte GB, Gomes THF, Sobral MFF: How Climate Variables Influence the Spread of SARS-CoV-19 in the United States. Sustainability 2020, 12. doi: $10.3390 /$ su12219192

92. Mangino $\mathrm{M}$, Roederer $\mathrm{M}$, Beddall MH, Nestle FO, Spector TD: Innate and adaptive immune traits are differentially affected by genetic and environmental factors. Nature Communications 2017, 8(1): 1-7

93. Lazar V, Ditu LM, Pircalabioru GG, Gheorghe I, Curutiu C, Holban AM, Maria P, Ariana PL, Chifiriuc MC: Aspects of gut microbiota and immune system interactions in infectious diseases, immunopathology, and cancer. Frontiers in Immunology 2018, 9 https://doi.org/10.3389/fimmu.2018.01830

94. Romeo J, Warnberg J, Pozo T, Marcos A: Role of physical activity on immune function. Proceeding of the Nutrition Society 2010, 69(3): 390-399.

95. Kruger K, Mooren FC, Pilat C: The immunomodulatory effects of physical activity. Current Pharmaceutical
Design 2016, 22(24): 3730-3748. https://doi.org/10.2174/1381612822666160322145107.

96. Chen N, Zhou M, Dong X, Qu J, Gong F, Han Y, Qiu Y, Wang J, Liu Y, Wei Y, Xia, J, Yu, T, Zhang, X., Zhang L: Epidemiological and clinical characteristics of 99 cases of 2019 novel coronavirus pneumonia in Wuhan, China: a descriptive study. Lancet 2020, 395: 507-513. doi: 10.1016/S0140-6736(20)30211-7

97. Scartoni FR, Sant'Ana LDO, Murillo-Rodriguez E, Yamamoto T, Imperatori C, Budde H, Vianna MJ, Machado S: Physical Exercise and Immune System in the Elderly: Implications and Importance in COVID-19 Pandemic Period. Frontiers in Psychology, 2020, 11: 1-7.

98. Pinckard K, Baskin KK, Stanford, KI: Effects of exercise to improve cardiovascular health. Frontiers in the. Cardiovascular Medicine 2019, 6, 69. doi: 10.3389/fcvm.2019.00069

99. Maugeri G, Castrogiovanni P, Battaglia G, Pippi R, D'Agata V, Palma A, Di Rosa M, Musumeci G: The impact of physical activity on psychological health during Covid19 pandemic in Italy. Heliyon 2020, 6(6). https://doi.org/10.1016/j.heliyon.2020.e04315.

100. Wu Y, Ho W, Huang, Jin DY, Li S, Liu SL, Liu X, Qiu J, Sang $\mathrm{Y}$, Wang $\mathrm{Q}$, Yuen $\mathrm{KY}$, Zheng ZM: SARS-CoV-2 is an appropriate name for the new coronavirus. Lancet 2020, 395: 949-950. doi: 10.1016/S0140-6736(20)30557-2.

101. Moreira A, Kekkonen R, Delgado L, Fonseca J, Korpela $\mathrm{R}$, Haahtela $\mathrm{T}$ : Nutritional modulation of exerciseinduced immunodepression in athletes: a systematic review and meta-analysis. European Journal of Clinical Nutrition 2007, 61(4), 443-460.

102. Nielsen HG: Exercise and immunity. Current Issues in Sports and Exercise Medicine 2013, 121-140.

103. Gleeson M: Immune function in sport and exercise. Journal of Applied Physiology 2007, 103(2): 693-699.

104. Donovan SM, Comstock SS: Human Milk Oligosaccharides Influence Neonatal Mucosal and Systemic Immunity. Annals of Nutrition and Metabolism 2016, 69, 42-51. doi: 10.1159/000452818.

105. Plaza-Diaz J, Fontana L, Gil A: Human Milk Oligosaccharides and Immune System Development. Nutrients 2018, 10, 1038.

https://doi.org/10.3390/nu10081038. 
106. Torres-Castro P, Abril-Gil M, Rodriguez-Lagunas MJ, Castell M, Perez-Cano FJ, Franch A: TGF-beta2, EGF, and FGF21 Growth Factors Present in Breast Milk Promote Mesenteric Lymph Node Lymphocytes Maturation in Suckling Rats. Nutrients 2018, 10: 1171. https://doi.org/10.3390/nu10091171.

107. Venter C, Eyerich S, Sarin T, Klatt KC: Nutrition and the Immune System: A Complicated Tango. Nutrients 2020, 12: 818. doi:10.3390/nu12030818

108. Kumar NG, Contaifer D, Madurantakam P, Carbone S, Price ET, Tassell BV, Brophy DF, Wijesinghe DS: Dietary Bioactive Fatty Acids as Modulators of Immune Function: Implications on Human Health Nutrients, 2019, 11: 2974; doi:10.3390/nu11122974

109. Brenner H: Vitamin D Supplementation to Prevent COVID-19 Infections and Deaths-Accumulating Evidence from Epidemiological and Intervention Studies Calls for Immediate Action, Nutrients 2021, 13: 411. https://doi.org/10.3390/nu13020411.

110. Jovic TH, Ali SR, Ibrahim N, Jessop ZM, Tarassoli SP, Dobbs TD, Holford P, Thornton CA, Whitaker IS: Could Vitamins Help in the Fight Against COVID-19? Nutrients 2020, 12(9): 2550. doi: 10.3390/nu12092550.

111. Bouillon R, Marcocci C, Carmeliet G, Bikle D, White JH Dawson-Hughes B, Lips P, Munns CF, Lazaretti-Castro M, Giustina A, Bilezikian J: Skeletal and Extraskeletal Actions of Vitamin D: Current Evidence and Outstanding Questions, Endocrine Reviews, 2019, 40(4): 1109-1151. doi: $10.1210 /$ er.2018-00126

112. Djoko KY, Ong CL, Walker MJ, McEwan AG: The Role of Copper and Zinc Toxicity in Innate Immune Defense against Bacterial Pathogens. Journal of Biological Chemistry 2015, 290(31):18954-18961. doi.10.1074/jbc.R115.647099.

113. Ward RJ, Crichton RR, Taylor DL, Corte LD, Srai SK, Dexter DT: Iron and the immune system. Journal of Neural Transmission 2011, 118: 315-328. https://doi.org/10.1007/s00702-010-0479-3.

114. La Fata G, Weber P, Mohajeri MH : Probiotics and the gut immune system: Indirect regulation. Probiotics Antimicrob. Proteins2018, 10, 11-21.

115. Markowiak P, Śliżewska K: Effects of Probiotics, Prebiotics, and Synbiotics on Human Health. Nutrients 2017: 9(9):1021. doi: 10.3390/nu9091021
116. Calder PC, Jackson AA: Undernutrition, infection and immune function. Nutrition Research Reviews 2000, 13 3-29. https://doi.org/10.1079/095442200108728981.

117. Moreno DA, Ilic N: Functional and Bioactive Properties of Food: The Challenges Ahead. Foods 2018, 7: 139; doi:10.3390/foods7090139.

118. Wang X, Ouyang YY, Liu J, Zhao G: Flavonoid intake and risk of CVD: a systematic review and meta-analysis of prospective cohort studies. The British Journal of Nutrition 2014, 111(1): 1-11.

119. Tapiero $H$, Townsend DM, Tew KD: The role of carotenoids in the prevention of human pathologies. Biomedicine and pharmacotherapy = Biomedecine and pharmacotherapie 2004, 58(2): 100-110.

120. Borgeraas H, Johnson LK, Skattebu J, Hertel JK, Hjelmesaeth J: Effects of probiotics on body weight, body mass index, fat mass and fat percentage in subjects with overweight or obesity: a systematic review and meta-analysis of randomized controlled trials. Obesity reviews: an official Journal of the International Association for the Study of Obesity 2018, 19(2): 219-232.

121. Ruan Y, Sun J, He J, Chen F, Chen R, Chen H: Effect of Probiotics on Glycemic Control: A Systematic Review and Meta-Analysis of Randomized, Controlled Trials. PloS one 2015, 10(7),

doi. 10.1371/journal.pone.0132121

122. Swanson D, Block R, Mousa SA: Omega-3 fatty acids EPA and DHA: health benefits throughout life. Advances in Nutrition 2012, 3(1): 1-7.

123. Cory H, Passarelli S, Szeto J, Tamez M, Mattei J: The Role of Polyphenols in Human Health and Food Systems: A Mini-Review. Frontiers in Nutrition 2018, 5: 87.

124. Hsu S: Compounds derived from epigallocatechin-3gallate (EGCG) as a novel approach to the prevention of viral infections. Inflammation and Allergy Drug Targets 2015, 14: 13-18. doi:10.2174/187152811466615102215012.

125. Parker S, May B, Zhang C, Zhang AL, Lu C, Xue CC: A pharmacological review of bioactive constituents of Paeonia lactiflora Pallas and Paeonia veitchii Lynch. Phytotherapy Research 2016, PTR 30: 1445-1473. doi: $10.1002 /$ ptr.5653 
126. Yang C, Zhi X, Xu H: Advances on Semisynthesis, Total Synthesis, and Structure-Activity Relationships of Honokiol and Magnolol Derivatives. Mini Reviews in Medicinal Chemistry 2016, 16(5): 404-426. https://doi.org/10.2174/1389557516666151120115558

127. Singh NA, Kumar $P$, Kumar JN: Spices and herbs: Potential antiviral preventives and immunity boosters during COVID-19. Phytotherapy Research 2021, 35(5): 2745-2757.

128. Higa S, Hirano T, Kotani M, Matsumoto M, Fujita A, Suemura M, Kawase I, Tanaka T: Fisetin, a flavonol, inhibits TH2-type cytokine production by activated human basophils. The Journal of Allergy and Clinical Immunology 2003, 111(6): 1299-1306 https://doi.org/10.1067/mai.2003.1456

129. Lalani S, Poh CL: Flavonoids as Antiviral Agents for Enterovirus A71 (EV-A71). Viruses 2020, 12(2): 184 https://doi.org/10.3390/v12020184

130. Weber JM, Ruzindana-Umunyana A, Imbeault L, Sircar S: Inhibition of adenovirus infection and adenain by green tea catechins. Antiviral Research 2003, 58(2): 167173. https://doi.org/10.1016/s0166-3542(02)00212-7

131. Ciesek S, von Hahn T, Colpitts CC, Schang LM, Friesland M, Steinmann J, Manns MP, Ott M, Wedemeyer $\mathrm{H}$ Meule man P, Pietschmann T, Steinmann E: The green tea polyphenol, epigallocatechin-3-gallate, inhibits hepatitis C virus entry. Hepatology 2011, 54(6): 19471955.

132. Calland N, Albecka A, Belouzard S, Wychowski C, Duverlie G, Descamps V, Hober D, Dubuisson J, Rouillé $Y$, Séron K: (-)-Epigallocatechin-3-gallate is a new inhibitor of hepatitis C virus entry. Hepatology 2012, 55(3): 720-729. https://doi.org/10.1002/hep.24803

133. Huang HC, Tao MH, Hung TM, Chen JC, Lin ZJ, Huang C: (-)-Epigallocatechin-3-gallate inhibits entry of hepatitis B virus into hepatocytes. Antiviral Research 2014, 111 100-111. doi: 10.1016/j.antiviral.2014.09.009

134. Carneiro BM, Batista MN, Braga A, Nogueira ML, Rahal P: The green tea molecule EGCG inhibits Zika virus entry. Virology, 2016, 496: 215-218. https://doi.org/10.1016/j.virol.2016.06.012

135. Hengphasatporn K, Kungwan N, Rungrotmongkol T: Binding pattern and susceptibility of epigallocatechin gallate against envelope protein homodimer of Zika virus: A molecular dynamics study. Journal of Molecular Liquids 2019, 274: 140-147.

136. Kaihatsu K, Yamabe M, Ebara Y: Antiviral Mechanism of Action of Epigallocatechin-3-O-gallate and Its Fatty Acid Esters. Molecules 2018, 23(10), 2475. https://doi.org/10.3390/molecules23102475

137. Hussein G, Miyashiro $H$, Nakamura N, Hattori $M$, Kakiuchi N, Shimotohno K: Inhibitory effects of sudanese medicinal plant extracts on hepatitis $C$ virus (HCV) protease. Phytotherapy research: PTR 2000, 14(7): 510-516. https://doi.org/10.1002/10991573(200011)14:7<510: aid-ptr646>3.0.co;2-b

138. Minami M, Kita M, Nakaya T, Yamamoto T, Kuriyama $\mathrm{H}$, Imanishi J: The inhibitory effect of essential oils on herpes simplex virus type-1 replication in vitro. Microbiology and Immunology 2003, 47: 681-684.

139. Reichling J, Schnitzler P, Suschke U, Saller R: Essential oils of aromatic plants with antibacterial, antifungal, antiviral, and cytotoxic properties--an overview. Forschende Komplementarmedizin 2009, 16(2), 79-90. https://doi.org/10.1159/000207196

140. Musarra-Pizzo M, Ginestra G, Smeriglio A, Pennisi R, Sciortino MT, Mandalari G: The Antimicrobial and Antiviral Activity of Polyphenols from Almond (Prunus dulcis L.) Skin. Nutrients 2019, 11(10): 2355. https://doi.org/10.3390/nu11102355

141. Al-Sereiti MR, Abu-Amer KM, Sen P: Pharmacology of rosemary (Rosmarinus officinalis Linn.) and its therapeutic potentials. Indian Journal of Experimental Biology 1999, 37(2): 124-130.

142. Kuhn MA, Winston D: Herbal therapy and supplements: a scientific and traditional approach. Lippincott Williams and Wilkins 2000.

143. Borges RS, Ortiz B, Pereira A, Keita H, Carvalho J: Rosmarinus officinalis essential oil: A review of its phytochemistry, anti-inflammatory activity, and mechanisms of action involved. Journal of Ethnopharmacology 2019, 229: 29-45. https://doi.org/10.1016/j.jep.2018.09.038

144. Marchioni I, Najar B, Ruffoni B, Copetta A, Pistelli L, Pistelli L: Bioactive Compounds and Aroma Profile of Some Lamiaceae Edible Flowers. Plants 2020, 9: 691. https://doi.org/10.3390/plants9060691. 
145. Cornara L, Ambu G, Trombetta D, Denaro, M, Alloisio S, Frigerio J, Labra M, Ghimire G, Valussi M, Smeriglio A: Comparative and Functional Screening of Three Species Traditionally used as Antidepressants: Valeriana officinalis L., Valeriana jatamansi Jones ex Roxb. and Nardostachys jatamansi (D.Don) DC. Plants 2020 9: 994. https://doi.org/10.3390/plants9080994.

146. Boudjelal A, Smeriglio A, Ginestra G, Denaro M, Trombetta D: Phytochemical Profile, Safety Assessment and Wound Healing Activity of Artemisia absinthium L. Plants 2020, $\quad$ 9: 1744 https://doi.org/10.3390/plants9121744.

147. Chepel V, Lisun V, Skrypnik L: Changes in the Content of Some Groups of Phenolic Compounds and Biological Activity of Extracts of Various Parts of Heather (Calluna vulgaris (L.) Hull) at Different Growth Stages. Plants 2020: 9(8):

926. https://doi.org/10.3390/plants9080926

148. Chávez R, Fierro F, García-Rico RO, Vaca I: Filamentous fungi from extreme environments as a promising source of novel bioactive secondary metabolites. Frontiers in Microbiology 2015, 6: 903

\section{https://doi.org/10.3389/fmicb.2015.00903}

149. McCarty MF, DiNicolantonio JJ: Nutraceuticals have potential for boosting the type 1 interferon response to RNA viruses including influenza and coronavirus. Progress in Cardiovascular Diseases 2020, 63(3): 383385. https://doi.org/10.1016/j.pcad.2020.02.007

150. Rocha PdSd, Paula VMB, Olinto SCF, dos Santos EL, de Picoli Souza K, Estevinho LM: Diversity, Chemical Constituents and Biological Activities of Endophytic Fungi Isolated from Schinus terebinthifolius Raddi. Microorganisms 2020, 8 859. https://doi.org/10.3390/microorganisms 8060859.

151. El-Demerdash A: Chemical diversity and biological activities of Phaeosphaeria fungi genus: a systematic review. Journal of Fungi 2018, 4(4): 130. doi:10.3390/jof4040130

152. Specian V, Sarragiotto MH, Pamphile JA, Clemente E: Chemical characterization of bioactive compounds from the endophytic fungus Diaporthe helianthi isolated from Luehea divaricata. Brazilian Journal of Microbiology 2012, 43(3): 1174-1182. doi:10.1590/S1517-838220120003000045.
153. Alves MJ, Ferreira IC, Dias J, Teixeira V, Martins A, Pintado M: A review on antifungal activity of mushroom (basidiomycetes) extracts and isolated compounds. Current Topics in Medicinal Chemistry 2013, 13(21): $2648-2659$.

\section{https://doi.org/10.2174/15680266113136660191}

154. Reis FS, Martins A, Barros L, Ferreira IC: Antioxidant properties and phenolic profile of the most widely appreciated cultivated mushrooms: a comparative study between in vivo and in vitro samples. Food and chemical toxicology: an international journal published for the British Industrial Biological Research Association 2012, 50(5): 1201-1207. https://doi.org/10.1016/j.fct.2012.02.013

155. Chen J, Seviour R: Medicinal importance of fungal beta(1-->3), (1-->6)-glucans. Mycological Research 2007, 111(Pt 6): 635-652. https://doi.org/10.1016/j.mycres.2007.02.011

156. Li Y, Zhang G, Ng TB, Wang $\mathrm{H}$ : A novel lectin with antiproliferative and HIV-1 reverse transcriptase inhibitory activities from dried fruiting bodies of the monkey head mushroom Hericium erinaceum. Journal of Biomedicine and Biotechnology 2010. https://doi.org/10.1155/2010/716515

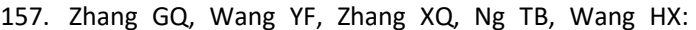
Purification and characterization of a novel laccase from the edible mushroom Clitocybe maxima. Process Biochemistry 2010, 45: 627-633. doi: 10.1016/j.procbio.2009.12.010

158. Gu CQ, Li JW, Chao F, Jin M, Wang XW, Shen ZQ: Isolation, identification and function of a novel antiHSV-1 protein from Grifola frondosa. Antiviral Research 2007, 75(3): 250-257. https://doi.org/10.1016/j.antiviral.2007.03.011

159. Mothana RA, Awadh Ali NA, Jansen R, Wegner U, Mentel R, Lindequist U: Antiviral lanostanoid triterpenes from the fungus Ganoderma pfeifferi. Fitoterapia, 2003, 74(1-2): 177-180. https://doi.org/10.1016/s0367-326x(02)00305-2

160. Obodai M, Mensah DLN, Fernandes A, Kortei, NK, Dzomeku M, Teegarden M, Schwartz SJ, Barros LB, Prempeh J, Takli RK, and Ferreira ICFR: Chemical Characterization and Antioxidant Potential of Wild 
Ganoderma Species from Ghana. Molecules 2017, 22 196. doi:10.3390/molecules22020196.

161. Ferreira ICFR, Heleno SA, Reis FSZ, Stojkovic D, Queiroz MJRP, Vasconcelos MH, and Sokovic M: Chemical features of Ganoderma polysaccharides with antioxidant, antitumor and antimicrobial activities. Phytochemistry 2015, 114: 38-55.

162. Habtemariam S: Trametes versicolor (Synn. Coriolus versicolor) Polysaccharides in Cancer Therapy: Targets and Efficacy Solomon. Biomedicines 2020, 8: 135. doi:10.3390/biomedicines8050135.

163. Carballo C, Pinto PIS, Mateus AP, Berbel C, Guerreiro CC, Martinez-Blanch JF, Codoñer, FM, Mantecon L, Power DM, Manchado M: Yeast $\beta$-glucans and microalgal extracts modulate the immune response and gut microbiome in Senegalese sole (Solea senegalensis). Fish \& Shellfish Immunology 2019, 92: 31-39. doi 10.1016/j.fsi.2019.05.044.

164. McCarty MF, DiNicolantonio JJ: Nutraceuticals have potential for boosting the type 1 interferon response to RNA viruses including influenza and coronavirus. Progress in Cardiovascular Diseases 2020, 63(3): 383385. https://doi.org/10.1016/j.pcad.2020.02.007

165. Wang JH, Lu LX, Zuo JH: Effect observation on Polyporus umbellatus polysaccharide and Buqi Jiedu Tang for treatment of chronic hepatitis B. Chinese Journal of Integrated Traditional and Western Medicine on Liver Diseases 1994, 4(2): 35 - 36.

166. Gordon M, Bihari B, Goosby E, Gorter R, Greco M, Guralnik M, Mimura T, Rudinicki V, Wong R, and Kaneko $\mathrm{Y}$ : A placebo-controlled trial of the immune modulator lentinan, in HIV-positive patients: a phase I/II trial. Journal of Medicine 1998, 29(5-6): 305-330.

167. Lönnerdal B: Nutritional and physiologic significance of human milk proteins. The American Journal of Clinical Nutrition 2003, $\quad$ 77(6): $\quad$ 1537S-1543S https://doi.org/10.1093/ajcn/77.6.1537S

168. Ng TB, Cheung RC, Wong JH, Wang Y, Ip DT, Wan DC, Xia J: Antiviral activities of whey proteins. Applied Microbiology and Biotechnology 2015, 99(17): 69977008. https://doi.org/10.1007/s00253-015-6818-4

169. Lucarini M: Bioactive Peptides in Milk: From Encrypted Sequences to Nutraceutical Aspects. Beverages, 2017, 3: 41. doi:10.3390/beverages3030041.
170. Michaelidou AM: Factors influencing nutritional and health profile of milk and milk products Small Rumininant Research 2008, 79: 42-50, 10.1016/j.smallrumres.2008.07.007

171. Ahmed A, Siman-Tov G, Hall G, Bhalla N, Narayanan A: Human Antimicrobial Peptides as Therapeutics for Viral Infections. Viruses 2019, 11(8): 704. https://doi.org/10.3390/v11080704

172. Badani H, Garry RF, Wimley WC: Peptide entry inhibitors of enveloped viruses: the importance of interfacial hydrophobicity. Biochimica et Biophysica Acta 2014, 1838(9): 2180-2197.

173. Wang $Q$, Sheng $X$, Shi A, Hu H, Yang Y, Liu L, Fei L, Liu H: $\beta$-Glucans: Relationships between Modification, Conformation and Functional Activities. Molecules 2017, 22(2): 257. https://doi.org/10.3390/molecules22020257

174. Brück WM, Graverholt G, Gibson GR: Use of batch culture and a two-stage continuous culture system to study the effect of supplemental alpha-lactalbumin and glycomacropeptide on mixd populations of human gut bacteria. FEMS Microbiology Ecology 2002, 41(3), 231$237 . \quad$ https://doi.org/10.1111/j.15746941.2002.tb00984.x

175. Jenssen H, Hancock RE: Antimicrobial properties of lactoferrin. Biochimie 2009: 91(1), 19-29.

176. Oo TZ, Cole N, Garthwaite L, Willcox MD, Zhu H: Evaluation of synergistic activity of bovine lactoferricin with antibiotics in corneal infection. The Journal of Antimicrobial Chemotherapy 2010, 65(6): 1243-1251. https://doi.org/10.1093/jac/dkq106

177. Agarwal G, Gabrani R: Antiviral Peptides: Identification and Validation. International Journal of Peptide Research and Therapeutics 2020, 1-20. https://doi.org/10.1007/s10989-020-10072-0

178. Berlutti F, Pantanella F, Natalizi T, Frioni A, Paesano R, Polimeni A, Valenti P: Antiviral properties of lactoferrina natural immunity molecule. Molecules 2011, 16(8): 6992-7018. https://doi.org/10.3390/molecules16086992

179. Carvalho C, Casseb S, Gonçalves RB, Silva E, Gomes A, Vasconcelos P: Bovine lactoferrin activity against Chikungunya and Zika viruses. The Journal of General 
Virology 2017, $\quad 98(7): \quad$ 1749-1754 https://doi.org/10.1099/jgv.0.000849

180. Saeland $E$, de Jong MA, Nabatov AA, Kalay $H$, Geijtenbeek TB, van Kooyk Y: MUC1 in human milk blocks transmission of human immunodeficiency virus from dendritic cells to T cells. Molecular Immunology 2009, 46(11-12), 2309-2316.

181. Koning N, Kessen SF, Van Der Voorn JP, Appelmelk BJ, Jeurink PV, Knippels LM, Garssen J, Van Kooyk Y: Human Milk Blocks DC-SIGN-Pathogen Interaction via MUC1. Frontiers in Immunology 2015, 6: 112. https://doi.org/10.3389/fimmu.2015.00112

182. Spitsberg VL: Invited review: Bovine milk fat globule membrane as a potential nutraceutical. Journal of Dairy Science 2005, 88(7): 2289-2294. https://doi.org/10.3168/jds.S0022-0302(05)72906-4

183. Taha SH, Mehrez, MA, Sitohy MZ, Abou Dawood AG, Abd-El Hamid MM, Kilany WH: Effectiveness of esterified whey proteins fractions against Egyptian Lethal Avian Influenza A (H5N1). Virology Journal 2010, 7: 330. https://doi.org/10.1186/1743-422X-7-330

184. Hubbard NE, Chapkin RS, Erickson KL: Effect of Dietary Linseed Oil on Tumoricidal Activity and Eicosanoid Production in Murine Macrophages, Lipids 1994, 29 651-655.

185. Perini JÂ de L, Stevanato FB, Sargi SC, Visentainer JEL, Dalalio MM de O, Matshushita M, De Souza NE, Visentainer JV: Ácidos graxos poli-insaturados n-3 e n-6: Metabolismo em mamíferos e resposta imune. Revista de Nutricao 2010, 23(6), 1075-1086. https://doi.org/10.1590/S1415-52732010000600013

186. Chen J, Wang L, Thompsop LU: Flaxseed and its components reduce metastasis after surgical excision of solid human breast tumor in nude mice. Cancer letters 2006, 234(2), 168-175.

https://doi.org/10.1016/j.canlet.2005.03.056

187. Gutiérrez S, Svahn SL, Johansson ME: Effects of Omega3 Fatty Acids on Immune Cells. International Journal of Molecular Sciences 2019, 20(20): 5028 https://doi.org/10.3390/ijms20205028.

188. Yessoufou A, Plé A, Moutairou K, Hichami A, and Khan NA: Docosahexaenoic acid reduces suppressive and migratory functions of $C D 4+C D 25+$ regulatory T-cells.
Journal of Lipid Research 2009, 50(12): 2377-2388. https://doi.org/10.1194/jlr.M900101-JLR200

189. Sorensen LS, Thorlacius-Ussing $\mathrm{O}$, Rasmussen $\mathrm{HH}$, Lundbye-Christensen S, Calder PC, Lindorff-Larsen K, Schmidt EB: Effects of perioperative supplementation with omega-3 fatty acids on leukotriene $B_{4}$ and leukotriene $B_{5}$ production by stimulated neutrophils in patients with colorectal cancer: a randomized, placebocontrolled intervention trial. Nutrients 2014, 6(10): 4043-4057. https://doi.org/10.3390/nu6104043

190. Gurzell EA, Teague H, Harris M, Clinthorne J, Shaikh SR, Fenton JI: DHA-enriched fish oil targets B cell lipid microdomains and enhances ex vivo and in vivo B cell function. Journal of Leukocyte Biology 2013, 93(4): 463470. https://doi.org/10.1189/jlb.0812394

191. Hashimoto M, Hossain S: Fatty Acids: From Membrane Ingredients to Signaling Molecules. In: Waisundara V., editor. Biochemistry and Health Benefits of Fatty Acids. IntechOpen Limited; London, UK, 2018.

192. Das UN: Can Bioactive Lipids Inactivate Coronavirus (COVID-19)? Archives of Medical Research 2020a, 51(3): 282-286.

https://doi.org/10.1016/j.arcmed.2020.03.004

193. Bari M, Bisogno $T$, Battista N: Bioactive Lipids in Health and Disease. Biomolecules 2021, 10: 1698

194. Wink P: Potential of DNA Intercalating Alkaloids and Other Plant Secondary Metabolites against SARS-CoV-2 Causing COVID-19. Diversity 2020, 12(5), 175. https://doi.org/10.3390/d12050175.

195. Harmer D, Gilbert M, Borman R, Clark KL: Quantitative mRNA expression profiling of ACE 2, a novel homologue of angiotensin converting enzyme. FEBS Letters 2002, 532: 107-110.

196. Kuba K, Imai Y, Ohto-Nakanishi T: Trilogy of ACE2: A peptidase in the renin-angiotensin system, a SARS receptor, and a partner for amino acid transporters. Pharmacology and Therapeutics 2010, 128: 119-128.

197. Jiang $F$, Yang J, Zhang $Y$, Dong $M$, Wang S, Zhang $Q$, Liu $\mathrm{FF}$, Zhang K, Zhang C: Angiotensin-converting enzyme 2 and angiotensin 1-7: novel therapeutic targets. Nature Reviews Cardiology 2014, 11: 413-426.

198. Zhou P, Yang XL, Wang XG, Hu B, Zhang L, Zhang W, Si HR, Zhu Y, Li B, Huang CL, Chen HD, Chen J, Luo Y, Guo H, Jiang RD, Liu MQ, Chen Y, Shen XR, Wang X, Zheng XS, 
Zhao K, Chen QJ, Deng F, Liu LL, Yan B, Zhan FX, Wang

YY Xiao GF, Shi ZL: A pneumonia outbreak associated with a new coronavirus of probable bat origin. Nature 2020, 579: 270-273.

199. Hoffman M, Kleine-Weber $H$, Schroeder S, Kruger $N$, Herrler T, Erichsen S, Schiergens T, Herrler G, Wu N-H, Nitsche A, Muller MA, Drosten C, Pohlmann S: SARS CoV-2 Cell Entry Depends on ACE2 and TMPRSS2 and Is Blocked by a Clinically Proven Protease Inhibitor. Cell 2020, 181: 271-280.

200. Bosch BJ, van der Zee R, de Haan CA, Rottier PJ: The coronavirus spike protein is a class I virus fusion protein: structural and functional characterization of the fusion core complex. Journal of Virology 2003, 77: 8801-8811.

201. Sivaraman D, Pradeep PS: Scope of phytotherapeutics in targeting ACE2 mediated Host-Viral Interface of SARS CoV2 that causes COVID-19. ChemRxiv, Preprint. 2020 https://doi.org/10. 26434/chemrxiv.12089730.v1.

202. Das, UN: Reply to: Bioactive Lipids and Coronavirus (COVID-19)-further Discussion. Archives of Medical Research 2020b, 51(5), 445 - 449. 10.1016/j.arcmed.2020.04.004.

203. Wahedi HM, Ahmad S, Abbasi SW: Stilbene-based Natural Compounds as Promising Drug Candidates against COVID-19. Journal of Biomolecular Structure and Dynamics 2020, 1-10 https://doi.org/10.1080/07391102.2020.1762743.

204. Sheybani Z, Dokoohaki MH, Negahdaripour M, Dehdashti M, Zolghadr H, Moghadami M, Masoompour SM, Zolghadr AR: The Role of Folic Acid in the Management of Respiratory Disease Caused by COVID 19. ChemRxiv, Preprint 2020. https://doi.org/10.26434/chemrxiv.12034980.v1.

205. Adem S, Eyupoglu V, Sarfraz I, Rasul A, Ali M: Identification of Potent COVID-19 Main Protease (Mpro) Inhibitors from Natural Polyphenols: An in Silico Strategy Unveils a Hope against CORONA. Preprints. 2020, 2020030333. doi:10. 20944/PREPRINTS202003. 0333. V1.

206. Bhatia S, Giri S, Lal AF, Singh S: Battle Against Coronavirus: Repurposing Old Friends (Food Borne Polyphenols) for New Enemy (COVID-19). ChemRxiv. Preprint 2020, https://doi. org/10. 26434/chemrxiv. 12108546. v1
207. Khalifa I, Zhu W, Nafie MS, Dutta K, Li C: Anti-COVID-19 Effects of Ten Structurally Different Hydrolysable Tannins through Binding with the Catalytic-Closed Sites of COVID-19 Main Protease: An In-Silico Approach. Preprints, $2020 \quad 2020030277$ https://www.preprints.org/manuscript/202003.0277/v1.

208. Maiti S, Banerjee A: Epigallocatechin-Gallate and Theaflavin-Gallate Interaction in SARS CoV-2 SpikeProtein Central-Channel with Reference to the Hydroxychloroquine Interaction: Bioinformatics and Molecular Docking Study. Preprints 2020, 2020040247. https://www.preprints.org/manuscript/202004.0247/v1.

209. Pendyala B, Patras A: In silico Screening of Food Bioactive Compounds to Predict Potential Inhibitors of COVID-19 Main protease (Mpro) and RNA-dependent RNA polymerase (RdRp). ChemRxiv, Preprint 2020. https://doi.org/10.26434/chemrxiv.12051927.v2.

210. Serseg T, Benarous K, Yousfi M: Hispidin and Lepidine E: two Natural Compounds and Folic acid as Potential Inhibitors of 2019-novel coronavirus Main Protease (2019-nCoVMpro), molecular docking and SAR study. Current Computer-Aided Drug Design. Preprint 2020, arXiv:2004.08920.

https://doi.org/10.2174/1573409916666200422075440.

211. Utomo RY, Ikawati M, Meiyanto E: Revealing the Potency of Citrus and Galangal Constituents to Halt SARS-CoV-2 Infection. Preprints 2020, 2020030214. https://www.preprints.org/manuscript/202003.0214/v1.

212. Tallei TE, Tumilaar SG, Niode NJ, Fatimawali F, Kepel BJ, Idroes R, Effendi Y: Potential of Plant Bioactive Compounds as SARS-CoV-2 Main Protease (Mpro) and Spike (S) Glycoprotein Inhibitors: A Molecular Docking Study. Preprints 2020, https://www.preprints.org/manuscript/202004.0102/v1.

213. Smith M, Smith JC: Repurposing therapeutics for COVID-19: Supercomputer-based docking to the SARSCoV-2 viral spike protein and viral spike protein-human ACE2 interface. Chem-Rxiv, Preprint. 2020. https://doi.org/10.26434/chemrxiv.11871402.v3.

214. Yang $Y$, Islam MS, Wang J, Li Y, Chen X: Traditional Chinese Medicine in the Treatment of Patients Infected with 2019-New Coronavirus (SARS-CoV-2): A Review and Perspective. International Journal of Biological Sciences 2020, 16: 1708-1717. 
215. Ross JA, Kasum CM: Dietary flavonoids: Bioavailability, metabolic effects, and safety. Annual Review of Nutrition 2002, 22: 19-34.

216. Theoharides TC: COVID-19, pulmonary mast cells, cytokine storms, and beneficial actions of luteolin. Biofactors 2020, 46(3): 306-308 https://doi.org/10.1002/biof.1633.

217. Murphy EJ, Masterson C, Rezoagli E, O'Toole D, Major I, Stack GD, Lynch M, Laffey JG, Rowan NJ: $\beta$-Glucan extracts from the same edible shiitake mushroom Lentinus edodes produce differential in-vitro immunomodulatory and pulmonary cytoprotective effects - Implications for coronavirus disease (COVID19) immunotherapies. The Science of the Total Environment 2020, 732.

https://doi.org/10.1016/j.scitotenv.2020.139330

218. Zhang W, Zhao Y, Zhang F, Wang Q, Li T, Liu Z, Wang J, Qin Y, Zhang X, Yan X, Zeng Z, Zhang S: The use of antiinflammatory drugs in the treatment of people with severe coronavirus disease 2019 (COVID-19): The Perspectives of clinical immunologists from China. Clinical Immunology 2020: 1-5.

https://www.ncbi.nlm.nih.gov/pubmed/32222466.

219. Conti P, Ronconi G, Caraffa A, Gallenga CE, Ross R Frydas I, Kritas SK: Induction of pro-inflammatory cytokines (IL-1 and IL-6) and lung inflammation by Coronavirus-19 (COVID-19 or SARS-CoV-2): antiinflammatory strategies. Journal of Biological Regulators and Homeostatic Agents 2020, 34(2): 1. doi:10.23812/CONTI-E.

220. Laffey JG, Matthay MA: Fifty Years of Research in ARDS Cell Based Therapy for ARDS: Biology and Potential Therapeutic Value. American Journal of Respiratory and Critical Care Medicine 2017, 196: 266-273.

221. Chousterman BG, Swirski FK, Weber GF: Cytokine storm and sepsis disease pathogenesis. Seminars in Immunopathology 2017, 39: 517-528.

222. Masterson $\mathrm{CH}$, Murphy E, Major I, Gonzalez H, O’Toole D, McCarthy S, Laffey JG, Rowan N: Purified beta-glucan from the Lentinus edodes mushroom attenuates antibiotic resistant Klebsiella pneumoniae-induced pulmonary sepsis. American Journal of Respiratory and Critical Care Medicine 2019, 199: A122. https://www. atsjournals. org/doi/abs/10. 1164/ajrccmconference. 2019. 199. 1_MeetingAbstracts. A1222.

223. McCarty SD, Horgan E, Ali A, Masterson C, Laffey JG, MacLoughlin R, O'Toole D: Nebulized mesenchemyal stem cells derived conditioned medium retains antibacterial properties against clinical pathogen isolates. Journal Aerosol Medicine and Pulmonary Drug Delivery 2019, 33

https://doi.org/10.1089/jamp.2019.1542.

224. Bedirli A, Kerem M, Pasaoglu H, Akyurek N, Tezcaner T, Elbeg S, Memis L, Sakrak O: Beta-glucan attenuates inflammatory cytokine release and prevents acute lung injury in an experimental model of sepsis. Shock 2007, 4: $397-401$

225. Luo H, Lv XD, Wang GE, Li YF, Kurihara H, He RR: Antiinflammatory effects of anthocyanins-rich extract from bilberry on crotron-oil-induced ear edema and Propionobacteracterium acnes plus LPS-induced liver damage in mice. International Journal of Food Science and Nutrition, 2014, 65, 594-601.

226. Xu W, Zhou Q, Yao Y, Li X, Zhang J-I, Su GH, Deng AP: Inhibitory effect of Gardanblue bluberry anthocyanin extracts on liposaccharide-stimulated inflammation response in RAW 264.7 cell. Journal Zheinjiang Uni-Sci B (Biomed and Biotech) 2016: 17: 425-436.

227. Roth M, Fang L, Stolz D, Tamm M: Pelargonium sidoides radix extract EPs 7630 reduces rhinovirus infection through modulation of viral binding proteins on human bronchial epithelial cells. PLoS One 2019, 14(2), doi. 10.1371/journal.pone.0210702

228. Sinha S, Cheng K, Aldape K, Schiff E, Ruppin E: Systematic Cell Line-Based Identification of Drugs Modifying ACE2 Expression. Preprints 2020. https://www.preprints.org/manuscript/202003.0446/v1.

229. Nonnecke BJ, McGill, JL, Ridpath JF, Sacco RE, Lippolis JD, Reinhardt TA: Acute phase response elicited by experimental bovine diarrhea virus (BVDV) infection is associated with decreased vitamin $D$ and $E$ status of vitamin-replete preruminant calves. Journal of Dairy Science 2014, 97, 5566-5579.

230. Jakovac H: COVID-19 and vitamin D-Is there a link and an opportunity for intervention? American Journal of Physiology-Endocrinology and Metabolism 2020, 318: E589. doi:10.1152/ajpendo. 00138. 2020. 
231. Ghavideldarestani $M$, Honardoost $M$, Khamseh $M E$ : Role of Vitamin D in Pathogenesis and Severity of COVID-19 Infection. Preprints 2020, 2020040355 https://www.preprints.org/manuscript/202004.0355/v1.

232. Ilie PC, Stefanescu S, Smith L: The role of vitamin D in the prevention of coronavirus disease 2019 infection and mortality. Aging Clinical and Experimental Research 2020. Article in Press https://doi.org/10.1007/s40520020-01570-8

233. Daneshkhah A, Agrawal V, Eshein A, Subramanian $H$, Roy HK, Backman V: The Possible Role of Vitamin D in Suppressing Cytokine Storm and Associated Mortality in COVID-19 Patients. medRxiv, Preprint 2020 https://doi.org/10.1101/2020.04.08.20058578.

234. Lau FH, Majumder R, Torabi R, Saeg F, Hoffman R, Cirillo JD, Greiffenstein, P. Vitamin D Insufficiency is Prevalent in Severe COVID-19. medRxiv, Preprint 2020 https://doi.org/10.1101/2020.04.24.20075838.

235. Nikhat S, Fazil M: Overview of Covid-19, its prevention and management in the light of Unani medicine. Science of The Total Environment 2020, 728. doi.10.1016/j.scitotenv.2020.138859

236. Liang $\mathrm{Y}$, Zhang Q, Zhang L, Wang $\mathrm{R}, \mathrm{Xu} \mathrm{X,} \mathrm{Hu} \mathrm{X:}$ Astragalus Membranaceus Treatment Protects Raw264. 7 Cells from Influenza Virus by Regulating G1 Phase and the TLR3-Mediated Signaling Pathway. Evidence-based Complementary and Alternative Medicine 2019, https://dx.doi.org/10.1155\%2F2019\%2F2971604.

237. Im K, Kim J, Min H: Ginseng, the natural effectual antiviral: Protective effects of Korean red ginseng against viral infection. Journal of Ginseng Research 2016, 40: 309-314.

238. Hui L, Qiao-ling T, Ya-xi S, Shi-bing L, Ming Y, Robinson $\mathrm{N}$, Jian-ping, L: Can Chinese Medicine Be Used for Prevention of Corona Virus Disease 2019 (COVID-19)? A Review of Historical Classics, Research Evidence and Current Prevention Programs. Chinese Journal of Integrative Medicine 2020, 26: 243-250.

239. Luo E, Zhang D, Luo H, Liu B, Zhao K, Zhao Y, Bian Y, Wang Y: Treatment efficacy analysis of traditional Chinese medicine for novel coronavirus pneumonia (COVID-19): an empirical study from Wuhan, Hube Province, China. Chinese Medicine 2020, 15, 34 https://cmjournal.biomedcentral.com/articles/10.1186 /s13020-020-00317-x.

240. Ang L, Lee HW, Choi JY, Zhang J, Lee MS: Herbal medicine and pattern identification for treating COVID19: A rapid review of guidelines. Integrative Medicine Research 2020, 9. https://doi. org/10. 1016/j. imr. 2020. 100407. 